Article

\title{
Synthesis and Antitumor Activity of New Thiazole Nortopsentin Analogs
}

\author{
Virginia Spanò, Alessandro Attanzio, Stella Cascioferro, Anna Carbone, Alessandra Montalbano, \\ Paola Barraja, Luisa Tesoriere, Girolamo Cirrincione, Patrizia Diana and Barbara Parrino * \\ Dipartimento di Scienze e Tecnologie Biologiche Chimiche e Farmaceutiche, STEBICEF, via Archirafi 32, \\ 90123 Palermo, Italy; virginia.spano@unipa.it (V.S.); alessandro.attanzio@unipa.it (A.A.); \\ stellamaria.cascioferro@unipa.it (S.C.); anna.carbone@unipa.it (A.C.); alessandra.montalbano@unipa.it (A.M.); \\ paola.barraja@unipa.it (P.B.); luisa.tesoriere@unipa.it (L.T.); girolamo.cirrincione@unipa.it (G.C.); \\ patrizia.diana@unipa.it (P.D.) \\ * Correspondence: barbara.parrino@unipa.it; Tel.: +39-91-238-97413 \\ Academic Editor: Orazio Taglialatela-Scafati \\ Received: 10 October 2016; Accepted: 5 December 2016; Published: 14 December 2016
}

\begin{abstract}
New thiazole nortopsentin analogs in which one of the two indole units was replaced by a naphthyl and/or 7-azaindolyl portion, were conveniently synthesized. Among these, three derivatives showed good antiproliferative activity, in particular against MCF7 cell line, with GI $_{50}$ values in the micromolar range. Their cytotoxic effect on MCF7 cells was further investigated in order to elucidate their mode of action. Results showed that the three compounds act as pro-apoptotic agents inducing a clear shift of viable cells towards early apoptosis, while not exerting necrotic effects. They also caused cell cycle perturbation with significant decrease in the percentage of cells in the G0/G1 and S phases, accompanied by a concomitant percentage increase of cells in the G2/M phase, and appearance of a subG1-cell population.
\end{abstract}

Keywords: marine alkaloids; bis-indolyl alkaloids; thiazolyl-indoles; apoptosis; antiproliferative activity

\section{Introduction}

In the latest decades, marine environment has increasingly provided a huge number of biologically active molecules. Among marine organisms, deep-sea sponges have contributed with several compounds endowed with antitumor activity [1-4]. The isolation of such molecules is very important since cancer is still an important social problem, in fact it is supposed to maintain as causes of death its primacy after heart and circulatory disorders. This scenario justifies the attention paid by a multitude of researchers in the individuation and development of natural or synthetic heterocyclic compounds as scaffold for antitumor agents [5-8]. Bis-indolyl alkaloids represent an important class of deep-sea sponge metabolites, useful as leads for antitumor agents. They are characterized by two indole units linked, through their position 3 , by a spacer $[9,10]$. The spacer can be an acyclic chain such as in hyrtiosin B, isolated from Hyrtios erecta [11], or a carbocyclic ring as in the case of asterriquinone, isolated from Aspergillus fungi [12]. Heterocyclic rings can also play as spacer for bis-indolyl alkaloids. Thus, dragmacidin isolated from the deep water sponges Dragmacidon, Halicortex bears a saturated six-membered piperazine ring (Chart 1) [13].

Topsentins A, B1 and B2, bearing a 2-acyl imidazole spacer, were isolated from Topsentia genitrix sponge [14].

Nortopsentins A-C, which exhibit a 2,4-disubstituted imidazole ring as a spacer, were isolated from Spongosorites ruetzleri, and showed in vitro cytotoxicity against P388 cells [15].

Due to their interesting cytotoxicity, nortopsentins attracted remarkable attention by researchers and several total syntheses of these natural products were reported [16-19]. Moreover, the synthesis 
and antiproliferative evaluation of analogs in which the imidazole ring of the natural compounds was replaced by several five-membered heterocycles such as bis-indolyl-thiophenes [20], -pyrazoles [21], -furans [22], [1,2] oxazoles [22], -pyrroles [23], and -1,2,4-thiadiazoles [24] (Chart 1), many of them showing antiproliferative activity often reaching $\mathrm{GI}_{50}$ values in the low micromolar range or even at sub-micromolar level, were reported.<smiles>O=C(C(=O)c1c[nH]c2[nH]ccc12)c1c[nH]c2ccc(O)cc12</smiles>

Hyrtiosin B<smiles>CN1CC(c2c[nH]c3cc(Br)ccc23)NCC1c1c[nH]c2c(Br)c(Br)cc(O)c12</smiles><smiles>C=CC(C)(C)n1cc(C2=C(O)C(c3cn(C(C)(C)C=C)c4ccccc34)=C(O)C(=O)C2=O)c2ccccc21</smiles><smiles>[R]c1ccc2c(C(=O)c3ncc(-c4c[nH]c5cc([R])ccc45)[nH]3)c[nH]c2c1</smiles>

Topsentin A $\mathrm{R}=\mathrm{R}_{1}=\mathrm{H}$ Topsentin B1 R=H; $\mathrm{R}_{1}=\mathrm{OH}$; Topsentin B2 $\mathrm{R}=\mathrm{Br} ; \mathrm{R}_{1}=\mathrm{OH}$;<smiles>[R]c1ccc2c(c1)c(-c1cn([R])c3ccc([R3])cc13)cn2[R]</smiles>

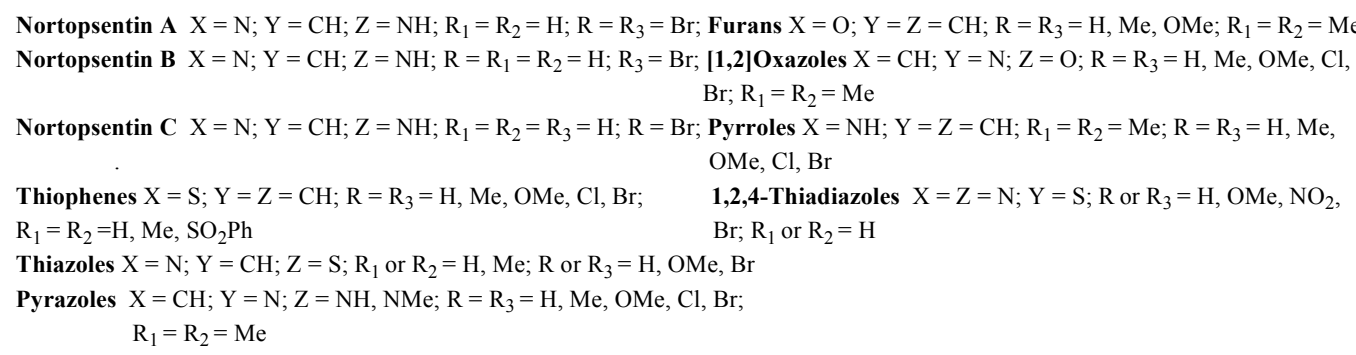

Chart 1. Bis-indolyl alkaloids.

Other structural manipulation of the natural product also involved one or both indole units producing 3-[(2-indolyl)-5-phenyl]pyridine and 3-(2-phenyl-1,3-thiazol-4-yl)-1H-7-azaindole derivatives, which showed significant antiproliferative activity and inhibited CDK1 (Chart 2) [25,26].

The interesting results obtained by the aza-substitution of the indole moiety, led to the synthesis and biological evaluation of 3-[2-(1H-indol-3-yl)-1,3-thiazol-4-yl]-1H-4-azaindoles and the corresponding $1 H$-7-azaindole derivatives (Chart 2) $[27,28]$. Both series showed potent antiproliferative activity against a wide range of cell lines, including diffuse malignant peritoneal mesothelioma (DMPM), a fatal disease, poorly responsive to conventional therapies, and acted as CDK1 inhibitors. Moreover, a derivative belonging to the 7-aza series, in the mouse model, by intraperitoneal administration was effective in a significant reduction of the DMPM at well tolerated doses. 




3-[(2-Indolyl)-5-phenyl]pyridine

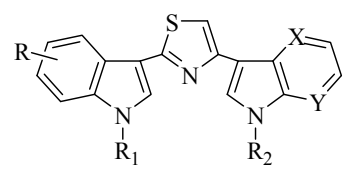

4-Aza series: $\mathrm{X}=\mathrm{N} ; \mathrm{Y}=\mathrm{CH}$ 7-Aza series: $\mathrm{X}=\mathrm{CH} ; \mathrm{Y}=\mathrm{N}$

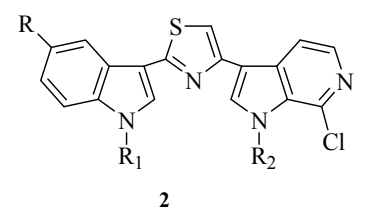

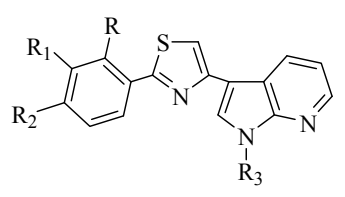

3-(2-Phenyl-1,3-thiazol-4-yl)-1H-7-azaindole


Chart 2. Nortopsentin analogs.

Lately, three new series of nortopsentin analogs of type 1, 2 and 3 (Chart 2) were efficiently synthesized and exhibited remarkable antiproliferative activity against several human tumor cell lines $[29,30]$.

Interestingly, a derivative of the series 2 at low concentrations $\left(\mathrm{GI}_{30}\right)$ caused morphological changes typical of autophagic death with massive formation of cytoplasmic acid vacuoles without apparent loss of nuclear material, and with arrest of cell cycle at the G1 phase, whereas higher concentrations $\left(\mathrm{GI}_{70}\right)$ induced apoptosis with arrest of cell cycle at the $\mathrm{G} 1$ phase [29].

Considering the interesting biological activity of nortopsentin analogs and in particular of 3-(2-phenyl-1,3-thiazol-4-yl)-1H-7-azaindole derivatives previously reported by us [26], herein we report the synthesis of new derivatives of type 4, 5 (Scheme 1) and $\mathbf{6}$ (Scheme 2), in which one of the two indole units was replaced by a naphthyl portion, to further investigate the contribution of the aryl moiety on biological activity. The antiproliferative activity of the novel compounds was evaluated in different human cancer cell lines and further studies were performed on the most active derivatives, in order to clarify their mechanism of action.

\section{Results and Discussion}

\subsection{Chemistry}

3-[2-(Naphthalen-2-yl)-1,3-thiazol-4-yl]-1H-indoles of type 4 and 3-[2-(naphthalen-2-yl)-1,3thiazol-4-yl]-1H-pyrrolo[2,3-b]pyridines of type $\mathbf{5}$ (Table 1 ) were conveniently synthesized by Hantzsch reaction between naphthalene-2-carbothioamide 17 and 3-haloacetyl compounds of type 11, 12, 15 and 16 (Scheme 1).

3-Haloacetyl intermediates 11c, 15a,b and 16a,b were obtained from the corresponding indole 9c or 7 -azaindoles $\mathbf{1 3 a}, \mathbf{b}$ and $\mathbf{1 4 a}, \mathbf{b}$ respectively, while compounds $\mathbf{1 1 d}$ was synthesized from the corresponding $\mathrm{N}$-methyl-1-(1H-indol-3-yl)ethanone $\mathbf{7 b}$, as previously reported $[29,30]$.

3-Haloacetyl compounds $\mathbf{1 1 a}, \mathbf{b}$ and $\mathbf{1 2 a}-\mathbf{c}$ were prepared (70\%-85\% and $60 \%-70 \%$, respectively), reacting their corresponding $\mathrm{N}$-methyl or $\mathrm{N}-\mathrm{SO}_{2} \mathrm{Ph}$ derivatives $\mathbf{9 a}, \mathbf{b}$ and $\mathbf{1 0} \mathbf{a}-\mathbf{c}$ with chloroacetyl chloride $\left(\mathrm{ClCOCH}_{2} \mathrm{Cl}\right)$ in presence of aluminum chloride $\left(\mathrm{AlCl}_{3}\right)$ in dichloromethane $(\mathrm{DCM})$; compound $12 \mathrm{~d}$ was obtained $(70 \%)$ from the corresponding $\mathrm{N}-\mathrm{SO}_{2} \mathrm{Ph} 1-(1 \mathrm{H}$-indol-3-yl)ethanone $7 \mathrm{c}$ using bromine in refluxing methanol $(\mathrm{MeOH})$.

Reaction of the synthesized key intermediates $11 \mathbf{a}-\mathbf{d}, \mathbf{1 2 a}-\mathbf{d}, \mathbf{1 5 a} \mathbf{a} \mathbf{b}$ and $\mathbf{1 6} \mathbf{a}, \mathbf{b}$ with naphthalene2-carbothioamide 17 in refluxing ethanol gave the 3-[2-(naphthalen-2-yl)-1,3-thiazol-4-yl]- $1 H$-indoles 
4a-h $\quad(48 \%-95 \%) \quad$ and $\quad 3-[2-(n a p h t h a l e n-2-y l)-1,3-t h i a z o l-4-y l]-1 H-p y r r o l o[2,3-b]$ pyridine $\quad 5 a-d$ $(55 \%-85 \%)$, respectively.

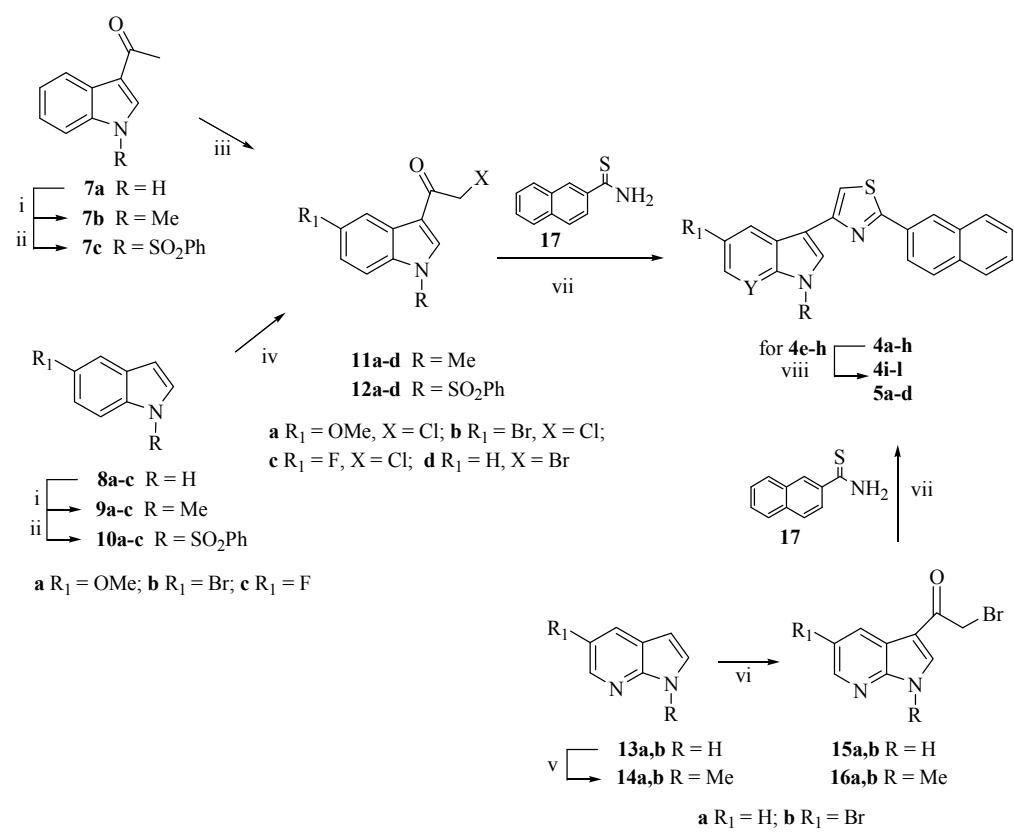

Scheme 1. Synthesis of substituted 3-[2-(naphthalen-2-yl)-1,3-thiazol-4-yl]-1H-indoles 4 and 3-[2-(naphthalen-2-yl)-1,3-thiazol-4-yl]-1H-pyrrolo[2,3-b]pyridine 5. Reagents: (i) (a) $t$-BuOK, toluene, TDA-1, rt, 1-24 h; (b) MeI, rt, 30 min-2 h, 80\%-98\%; (ii) (a) NaH, THF, $0{ }^{\circ} \mathrm{C}-\mathrm{rt}, 1 \mathrm{~h}$; (b) benzensulphonyl chloride, rt, 1-24 h, 87\%-90\%; (iii) $\mathrm{Br}_{2}$, methanol, reflux, $2 \mathrm{~h}, 40 \%-70 \%$; (iv) $\mathrm{AlCl}_{3}, \mathrm{DCM}, \mathrm{ClCOCH}_{2} \mathrm{Cl}$, rt, 1-5 h, 60\%-85\%; (v) (a) $t$-BuOK, toluene, TDA-1, rt, 3 h; (b) MeI, rt, 1 h, 96\%-99\%; (vi) $\mathrm{AlCl}_{3}$, $\mathrm{DCM}, \mathrm{BrCOCH}_{2} \mathrm{Br}$, reflux, $40 \mathrm{~min}, 70 \%-92 \%$; (vii) ethanol, $60{ }^{\circ} \mathrm{C}$-reflux, $30 \mathrm{~min}-12 \mathrm{~h}, 48 \%-95 \%$; and (viii) $\mathrm{NaOH}$, water, ethanol, reflux, $5-6 \mathrm{~h}, 50 \%-80 \%$.

Table 1. 3-[2-(naphthalen-2-yl)-1,3-thiazol-4-yl]-1H-indoles 4 and 3-[2-(naphthalen-2-yl)-1,3-thiazol4-yl]-1H-pyrrolo[2,3-b]pyridines 5 .

\begin{tabular}{|c|c|c|c|c|c|}
\hline Compound & Substrate & $\mathbf{R}$ & $\mathbf{R}_{1}$ & $Y$ & Yields (\%) \\
\hline \multicolumn{6}{|c|}{$\begin{array}{l}\text { 4a-l } \\
\text { 5a-d }\end{array}$} \\
\hline $4 a$ & $11 a$ & $\mathrm{Me}$ & $\mathrm{OMe}$ & $\mathrm{CH}$ & 95 \\
\hline $4 b$ & $11 b$ & $\mathrm{Me}$ & $\mathrm{Br}$ & $\mathrm{CH}$ & 72 \\
\hline $4 c$ & 11c & $\mathrm{Me}$ & F & $\mathrm{CH}$ & 48 \\
\hline $4 d$ & 11d & $\mathrm{Me}$ & $\mathrm{H}$ & $\mathrm{CH}$ & 75 \\
\hline $4 e$ & $12 a$ & $\mathrm{SO}_{2} \mathrm{Ph}$ & $\mathrm{OMe}$ & $\mathrm{CH}$ & 90 \\
\hline $4 f$ & $12 b$ & $\mathrm{SO}_{2} \mathrm{Ph}$ & $\mathrm{Br}$ & $\mathrm{CH}$ & 70 \\
\hline $4 g$ & $12 \mathrm{c}$ & $\mathrm{SO}_{2} \mathrm{Ph}$ & $\mathrm{F}$ & $\mathrm{CH}$ & 60 \\
\hline $4 \mathrm{~h}$ & $12 d$ & $\mathrm{SO}_{2} \mathrm{Ph}$ & $\mathrm{H}$ & $\mathrm{CH}$ & 94 \\
\hline $4 i$ & $4 e$ & $\mathrm{H}$ & $\mathrm{OMe}$ & $\mathrm{CH}$ & 50 \\
\hline $4 j$ & $4 f$ & $\mathrm{H}$ & $\mathrm{Br}$ & $\mathrm{CH}$ & 68 \\
\hline $4 k$ & $4 g$ & $\mathrm{H}$ & F & $\mathrm{CH}$ & 75 \\
\hline 41 & $4 \mathrm{~h}$ & $\mathrm{H}$ & $\mathrm{H}$ & $\mathrm{CH}$ & 80 \\
\hline $5 a$ & $16 a$ & $\mathrm{Me}$ & $\mathrm{H}$ & $\mathrm{N}$ & 75 \\
\hline $5 b$ & $16 \mathrm{~b}$ & $\mathrm{Me}$ & $\mathrm{Br}$ & $\mathrm{N}$ & 55 \\
\hline $5 c$ & $15 a$ & $\mathrm{H}$ & $\mathrm{H}$ & $\mathrm{N}$ & 80 \\
\hline $5 d$ & $15 b$ & $\mathrm{H}$ & $\mathrm{Br}$ & $\mathrm{N}$ & 85 \\
\hline
\end{tabular}


$\mathrm{N}-\mathrm{SO}_{2} \mathrm{Ph}$ protected indoles $10 \mathbf{a}-\mathbf{c}[31,32]$ and 1-(1H-indol-3-yl)ethanone $7 \mathbf{c}(90 \%)$ were synthesized from the commercially available indoles $8 \mathbf{a}-\mathbf{c}$ or $1-(1 H$-indol-3-yl)ethanone $7 \mathbf{a}$ by reaction with benzenesulphonyl chloride and sodium hydride (NaH), in tetrahydrofuran (THF); whereas methylated compounds $\mathbf{9 a}-\mathbf{c}$ and $\mathbf{7 b}$ were prepared as previously reported [26,30].

The subsequent deprotection of $\mathrm{N}-\mathrm{SO}_{2} \mathrm{Ph}$ derivatives $\mathbf{1 e}-\mathbf{h}$ using sodium hydroxide in ethanol under reflux afforded, after neutralization, the corresponding unprotected derivatives $4 \mathbf{i}-\mathbf{1}(50 \%-80 \%)$.

3-[4-(Naphthalene-2-yl)-1,3-thiazol-2-yl]-1H-indoles $\mathbf{6 a}-\mathbf{h}$ were synthesized (Table 2), also in this case, by Hantzsch reaction between the key intermediates indolo-3-carbothiamides 22d, 23a-d, 24a-c and naphthalene-2-acetylbromide 25, performed in dimethylformamide (DMF) under reflux (Scheme 2). In particular, reaction of naphthalene-2-acetylbromide 25 with $N$-Boc indolo-3-carbothiamides $24 a-c$ afforded the corresponding unprotected 3-[4-(naphthalene-2-yl)-1,3-thiazol-2-yl]-1H-indoles $\mathbf{6 e - h}$. Indolo-3-carbothiamides $\mathbf{2 2 d}, \mathbf{2 3} \mathbf{a}-\mathbf{d}$ and $\mathbf{2 4 a}-\mathbf{c}$ were prepared from the corresponding indoles $\mathbf{8 a}-\mathbf{d}$, $9 a-d$ and 18a-c through the formation of amides $19 d, 20 a-d$ and $21 a-c$ as previously reported by us [28].

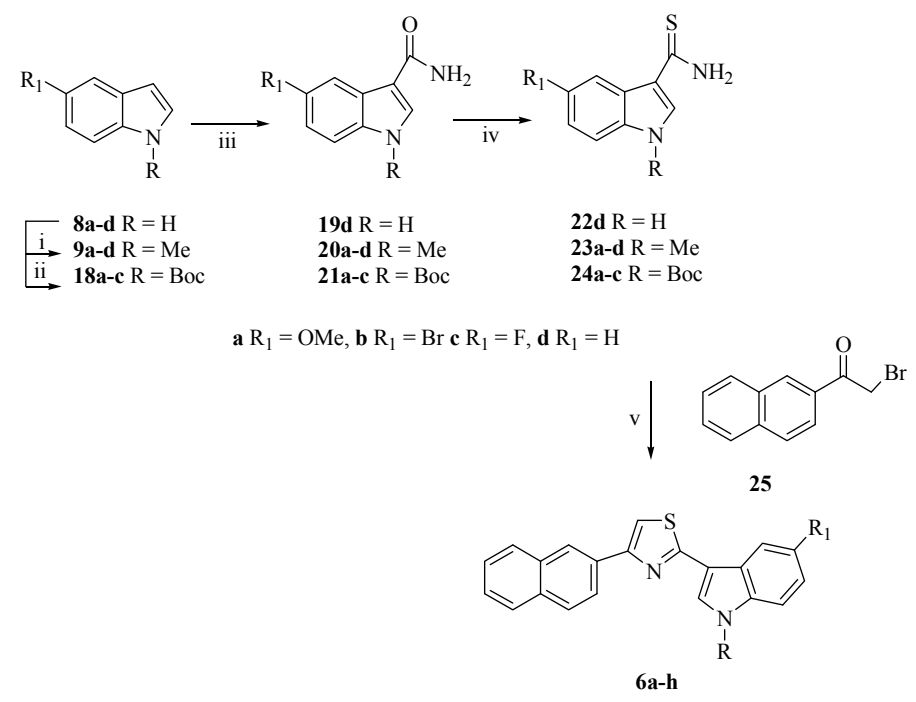

Scheme 2. Synthesis of 3-[4-(naphthalene-2-yl)-1,3-thiazol-2-yl]-1H-indoles 6a-h. Reagents: (i) (a) $t$-BuOK, toluene, TDA-1, rt, 6 h; (b) MeI, rt, 1 h, 96\%-98\%; (ii) Boc, triethylamine, THF, reflux, $24-48$ h, 90\%-100\%; (iii) (a) chlorosulphonyl isocyanide, acetonitrile, $0{ }^{\circ} \mathrm{C}$ then $\mathrm{rt} 0.5-2 \mathrm{~h}$ or reflux, $15 \mathrm{~min}$; (b) acetone/water 8:1, $\mathrm{KOH} \mathrm{10 \% ,40 \% -70 \% ;} \mathrm{(iv)} \mathrm{Lawesson's} \mathrm{reagent,} \mathrm{toluene,} \mathrm{reflux,} 0.5-24$ h, 90\%-98\%; (v) DMF, $60{ }^{\circ} \mathrm{C}$-reflux, 3-24 h, 48\%-99\%.

Table 2. 3-[4-(Naphthalene-2-yl)-1,3-thiazol-2-yl]-1H-indoles 6a-h.

\begin{tabular}{ccccc}
\hline Compound & Substrate & $\mathbf{R}$ & \\
\hline & & & & \\
\hline $\mathbf{6 a}$ & $\mathbf{2 3 a}$ & $\mathrm{Me}$ & $\mathrm{OMe}$ & 98 \\
$\mathbf{6 b}$ & $\mathbf{2 3 b}$ & $\mathrm{Me}$ & $\mathrm{Br}$ & 98 \\
$\mathbf{6 c}$ & $\mathbf{2 3 c}$ & $\mathrm{Me}$ & $\mathrm{F}$ & 75 \\
$\mathbf{6 d}$ & $\mathbf{2 3 d}$ & $\mathrm{Me}$ & $\mathrm{H}$ & 99 \\
$\mathbf{6 e}$ & $\mathbf{2 4 a}$ & $\mathrm{H}$ & $\mathrm{OMe}$ & 48 \\
$\mathbf{6 f}$ & $\mathbf{2 4 b}$ & $\mathrm{H}$ & $\mathrm{Br}$ & 75 \\
$\mathbf{6 g}$ & $\mathbf{2 4 c}$ & $\mathrm{H}$ & $\mathrm{F}$ & 60 \\
$\mathbf{6 h}$ & $\mathbf{2 2 d}$ & $\mathrm{H}$ & $\mathrm{H}$ & 60 \\
\hline
\end{tabular}




\subsection{Biology}

\subsubsection{Cytotoxic Activity}

All synthesized nortopsentin analogs 3-[2-(naphthalen-2-yl)-1,3-thiazol-4-yl]-1H-indoles 4a-1 3-[2-(naphthalen-2-yl)-1,3-thiazol-4-yl]-1H-pyrrolo[2,3-b]pyridines 5a-d, and 3-[4-(naphthalene-2-yl)1,3-thiazol-2-yl]- $1 \mathrm{H}$-indoles $\mathbf{6 a}-\mathbf{h}$, were tested at a single dose $\left(10^{-5} \mathrm{M}\right)$ for cytotoxicity against three human tumor cell lines, HCT 116 cells (colorectal carcinoma), MDA-MB-435 cells (melanoma) and MCF-7 cells (breast cancer) by MTT assay. In Table 3 are shown the growth percentages calculated for some of the nortopsentin analogs since those derivatives for which growth percentages higher than 90 were measured against all the three lines are not reported.

Table 3. One dose $\left(10^{-5} \mathrm{M}\right)$ cytotoxic activity of compounds 4-6.

\begin{tabular}{cccc}
\hline \multicolumn{4}{c}{ Growth Percent ${ }^{\mathbf{1}}$} \\
\hline Compound & HCT116 & MCF-7 & MDA-MB-435 \\
\hline $\mathbf{4 a}$ & $85.6 \pm 4.3$ & $24.9 \pm 1.9$ & $87.7 \pm 4.1$ \\
$\mathbf{4 c}$ & $87.6 \pm 5.2$ & $74.5 \pm 4.3$ & $87.9 \pm 5.3$ \\
$\mathbf{4 i}$ & $86.5 \pm 4.8$ & $84.8 \pm 5.4$ & $94.8 \pm 5.5$ \\
$\mathbf{5 b}$ & $91.7 \pm 5.4$ & $62.9 \pm 4.2$ & $96.4 \pm 4.9$ \\
$\mathbf{5 d}$ & $103.5 \pm 2.3$ & $47.1 \pm 3.0$ & $101.4 \pm 3.2$ \\
$\mathbf{6 a}$ & $87.9 \pm 3.8$ & $30.7 \pm 3.1$ & $70.1 \pm 4.2$ \\
$\mathbf{6 c}$ & $83.1 \pm 4.1$ & $50.3 \pm 4.8$ & $39.1 \pm 2.7$ \\
$\mathbf{6 d}$ & $95.3 \pm 4.5$ & $37.5 \pm 2.2$ & $82.2 \pm 5.1$ \\
$\mathbf{6 g}$ & $91.4 \pm 6.4$ & $41.6 \pm 2.9$ & $98.4 \pm 4.6$ \\
\hline
\end{tabular}

${ }^{1}$ Cells were treated with the compounds for $72 \mathrm{~h}$ and cell survival was measured by MTT assay in comparison to cells treated with vehicle alone (control), as reported in Section 3.2. Values are the mean $\pm \mathrm{SD}$ of two separate experiments carried out in duplicate.

Compounds $4 \mathbf{a}, \mathbf{6 a}$ and $\mathbf{6 d}$ appeared the most active compounds in inhibiting cell growth and their activity was further investigated on MCF-7 cells, which are the most sensitive to the cytotoxic property of the compounds. When assayed in the concentration range 0.1-100 $\mu \mathrm{M}$, they inhibited the growth of MCF-7 cells in dose-dependent manner (Figure 1) and on the basis of GI $_{50}$ value, the drug concentration effective in causing $50 \%$ inhibition of cell growth, compound 4 a appeared the most effective (Table 4).

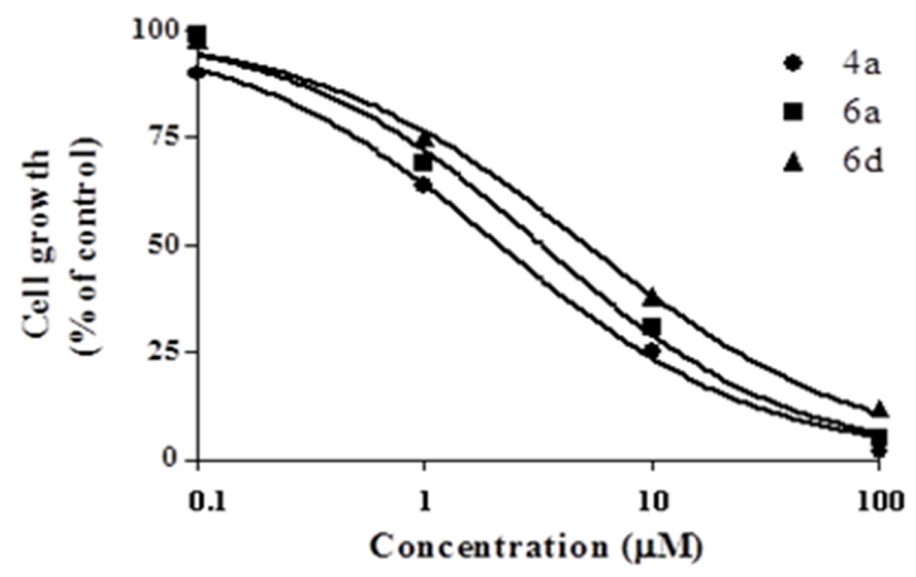

Figure 1. Effect of compounds $4 \mathbf{a}, \mathbf{6 a}$ and $\mathbf{6 d}$ on the growth of MCF-7. Cells were treated with the compounds for $72 \mathrm{~h}$ and cell survival was measured by MTT assay in comparison to cells treated with vehicle alone (control), as reported in Section 3.2. Values are the mean $\pm \mathrm{SD}$ of three separate experiments carried out in triplicate. 
Table 4. GI $_{50}$ values of the most active compounds $4 \mathbf{a}, \mathbf{6} \mathbf{a}$ and $\mathbf{6 d}$.

\begin{tabular}{cc}
\hline Compound & GI $_{\mathbf{5 0}}(\boldsymbol{\mu M})^{\mathbf{1}}$ \\
\hline $\mathbf{4 a}$ & $2.13 \pm 0.12$ \\
6a & $3.26 \pm 0.19$ \\
6d & $5.14 \pm 0.34$ \\
\hline
\end{tabular}

${ }^{1}$ Values were calculated using non-linear regression and are the mean $\pm \mathrm{SD}$ of three separate experiments carried out in triplicate.

\subsubsection{Cell Death Mechanism}

The mechanism of the most active compounds, $\mathbf{4 a}, \mathbf{6} \mathbf{a}$ and $\mathbf{6} \mathbf{d}$, in inducing cell death (necrosis or apoptosis) was investigated by double staining with propidium iodide (PI) and Annexin V-FITC followed by cytofluorimetric analysis. As shown in Figure 2, all three compounds induced a clear shift of viable cells towards early apoptosis in MCF-7 cells after $24 \mathrm{~h}$ treatment, while did not exert necrotic effects.

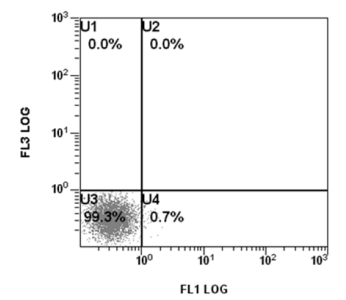

control

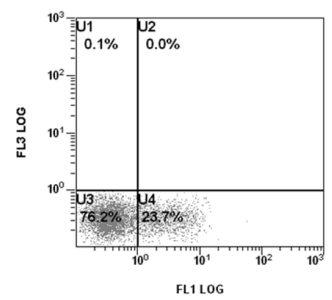

4a $5 \mu \mathrm{M}$

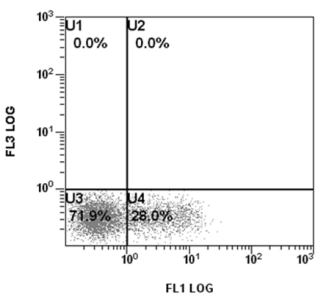

6а $\quad 15 \mu \mathrm{M}$



6d $35 \mu \mathrm{M}$

Figure 2. Flow cytometric analysis for the quantification by Annexin V/PI double staining of compounds 4a, 6a and $\mathbf{6 d}$ induced apoptosis in MCF-7 cells. Cell monolayers were incubated in the absence (control) or in the presence of the compounds at their relevant $\mathrm{GI}_{50}$ values. After $24 \mathrm{~h}$ incubation, cells were submitted to double staining with Annexin V/PI as reported in Section 3.2. U3, viable cells (Annexin V-/PI-); U4, cells in early apoptosis (Annexin V+/PI-); U2, cells in tardive apoptosis (Annexin V+/PI+); U1, necrotic cells (Annexin V-/PI+). Representative images of three experiments with comparable results.

\subsubsection{Cell Cycle Analysis}

The distribution of MCF-7 cells in the cell cycle phases after $24 \mathrm{~h}$ treatment with the three compounds $4 \mathbf{a}, \mathbf{6} \mathbf{a}$ and $\mathbf{6 d}$, was assessed by flow cytometric analysis after staining of DNA with PI. All synthesized compounds caused a significant decrease in the percentage of cells in the G0/G1 and S phases, accompanied by a concomitant percentage increase of cells in the G2/M phase, and appearance of a subG1-cell population (Figure 3).
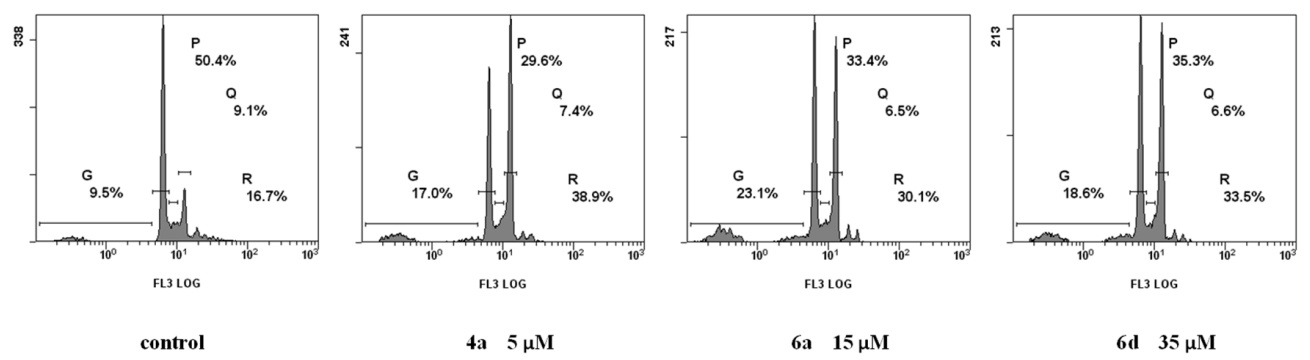

Figure 3. Cell cycle analysis of MCF-7 cells treated with compounds $4 \mathbf{a}, \mathbf{6 a}$ and $\mathbf{6} \mathbf{d}$. Cell monolayers were incubated in the absence (control) or in the presence of the compounds at their relevant $\mathrm{GI}_{50}$ values. After $24 \mathrm{~h}$ incubation, propidium iodide-stained cells were submitted to flow cytometric analysis as reported in Section 3.2. Representative images of three experiments with comparable results. 


\section{Materials and Methods}

\subsection{Chemistry}

\subsubsection{General}

All melting points were taken on a Büchi-Tottoly capillary apparatus. IR spectra were determined in bromoform with a Shimadzu FT/IR $8400 S$ spectrophotometer. ${ }^{1} \mathrm{H}$ and ${ }^{13} \mathrm{C}$ NMR spectra were measured at 200 and $50.0 \mathrm{MHz}$, respectively, in dimethylsulfoxide (DMSO)- $d_{6}$ solution, using a Bruker Avance II series $200 \mathrm{MHz}$ spectrometer. Compounds $5 \mathbf{c}$,d were characterized only by ${ }^{1} \mathrm{H}$ NMR spectra because of their poor solubility. Column chromatography was performed with Merk silica gel 230-400 mesh ASTM or with Büchi Sepacor chromatography module (prepacked cartridge system). Elemental analyses $(C, H, N)$ were within $\pm 0.4 \%$ of theoretical values and were performed with a VARIO EL III elemental analyzer. Purity of all the tested compounds was greater than 98\%, determined by HPLC. Compounds 7b [30], 9a-d [26], 10a-c [31,32], 11c,d [30], 14a,b, 15a,b, 16a,b, [29] 18a-c, $\mathbf{2 0 a}-\mathbf{d}, \mathbf{2 1} \mathbf{a}-\mathbf{c}, \mathbf{2 3 a}-\mathbf{d}$ and $\mathbf{2 4 a}-\mathbf{c}$ [28] were prepared as previously described by us.

\subsubsection{Synthesis of 1-[1-(Phenylsulfonyl)-1H-indol-3-yl]ethanone (7c)}

To a solution of the 3-acetylindole $7 \mathbf{a}(12.6 \mathrm{mmol})$ in anhydrous THF $(15.0 \mathrm{~mL})$ sodium hydride (60\% dispersion in mineral oil, $0.6 \mathrm{~g}, 12.6 \mathrm{mmol}$ ) was added at $0{ }^{\circ} \mathrm{C}$ and the mixture was stirred at room temperature for $1 \mathrm{~h}$. Benzensulfonyl chloride $(1.6 \mathrm{~mL}, 12.6 \mathrm{mmol})$ was added and the mixture was stirred at room temperature for 1-24 h. The residue was evaporated under reduced pressure, treated with water $(50 \mathrm{~mL})$ and extracted with EtOAc $(3 \times 50 \mathrm{~mL})$. The organic phase was dried $\left(\mathrm{Na}_{2} \mathrm{SO}_{4}\right)$, evaporated under reduced pressure and purified by column chromatography using DCM as eluent. Yield 90\%; analytical and spectroscopic data were previously reported [33].

3.1.3. Synthesis of Substituted 2-Chloro-1-(1-methyl-1H-indol-3-yl)ethanones (11a,b) and 2-Chloro-1-[1-(phenylsulfonyl)-1H-indol-3-yl]ethanones (12a-c)

A solution of the suitable indole $\mathbf{9 a}, \mathbf{b}, \mathbf{1 0 a}-\mathbf{c}(3.1 \mathrm{mmol})$ in anhydrous DCM $(12.0 \mathrm{~mL})$ was added dropwise at $0{ }^{\circ} \mathrm{C}$, under nitrogen atmosphere, to a stirred suspension of aluminum chloride $(2.9 \mathrm{~g}$, $21.7 \mathrm{mmol})$ in anhydrous DCM $(46.0 \mathrm{~mL})$. Then, chloroacetyl chloride $(0.8 \mathrm{~mL}, 9.3 \mathrm{mmol})$ was slowly added to the reaction mixture, which was stirred at room temperature for $1-5 \mathrm{~h}$ and then poured in ice and water $(60 \mathrm{~mL})$ and extracted with DCM $(3 \times 60 \mathrm{~mL})$. The organic phase was dried $\left(\mathrm{Na}_{2} \mathrm{SO}_{4}\right)$, evaporated under reduced pressure and purified by column chromatography using DCM as eluent.

2-Chloro-1-(5-methoxy-1-methyl-1H-indol-3-yl)ethanone (11a)

Conditions: room temperature for $1 \mathrm{~h}$; white solid; yield $85 \%$; mp: $227-228{ }^{\circ} \mathrm{C}$; IR: $1653(\mathrm{CO}) \mathrm{cm}^{-1}$; ${ }^{1} \mathrm{H}$ NMR (200 MHz, DMSO-d $\left.)_{6}\right) \delta: 3.80\left(\mathrm{~s}, 3 \mathrm{H}, \mathrm{CH}_{3}\right), 3.85\left(\mathrm{~s}, 3 \mathrm{H}, \mathrm{CH}_{3}\right), 4.80\left(\mathrm{~s}, 2 \mathrm{H}, \mathrm{CH}_{2}\right), 6.94(\mathrm{dd}$, $1 \mathrm{H}, J=2.5,8.9 \mathrm{~Hz}, \mathrm{H}-6), 7.49$ (d, 1H, J = 8.9 Hz, H-7), 7.68 (d, 1H, J = $2.5 \mathrm{~Hz}, \mathrm{H}-4), 8.40$ (s, 1H, H-2); ${ }^{13} \mathrm{C}$ NMR (50 MHz, DMSO-d 6 ) $\delta: 33.4(\mathrm{q}), 45.9$ (t), $55.1(\mathrm{q}), 102.8$ (d), 111.6 (d), 112.1 (s), 112.8 (d), 126.5 (s), 132.0 (s), 138.2 (d), 155.9 (s), 185.3 (s). Anal. Calcd. for $\mathrm{C}_{12} \mathrm{H}_{12} \mathrm{ClNO}_{2} \mathrm{C}(60.64 \%) \mathrm{H}(5.09 \%) \mathrm{N}$ (5.89\%) found C $(60.32 \%) \mathrm{H}(5.12 \%) \mathrm{N}(5.75 \%)$.

1-(5-Bromo-1-methyl-1H-indol-3-yl)-2-chloroethanone (11b)

Conditions: room temperature for $5 \mathrm{~h}$; dark brown solid; yield 70\%; mp: $175-176{ }^{\circ} \mathrm{C}$; IR 1658 (CO); ${ }^{1} \mathrm{H}$ NMR $\left(200 \mathrm{MHz}, \mathrm{DMSO}-d_{6}\right) \delta: 3.89\left(\mathrm{~s}, 3 \mathrm{H}, \mathrm{CH}_{3}\right), 4.85\left(\mathrm{~s}, 2 \mathrm{H}, \mathrm{CH}_{2}\right), 7.46(\mathrm{dd}, J=2.0,8.7 \mathrm{~Hz}, 1 \mathrm{H}, \mathrm{H}-6)$, $7.59(\mathrm{~d}, J=8.7 \mathrm{~Hz}, 1 \mathrm{H}, \mathrm{H}-7), 8.30(\mathrm{~d}, J=2.0 \mathrm{~Hz}, 1 \mathrm{H}, \mathrm{H}-4), 8.51$ (s, 1H, H-2); ${ }^{13} \mathrm{C}$ NMR $(50 \mathrm{MHz}, \mathrm{DMSO})$ $\delta: 33.6$ (q), 46.2 (t), 111.8 (s), 113.2 (d), 115.4 (s), 123.3 (d), 125.8 (d), 127.4 (s), 136.1 (s), 139.3 (d), 186.8 (s). Anal. Calcd. for $\mathrm{C}_{11} \mathrm{H}_{9}$ BrClNO C (46.11\%) H (3.17\%) N (4.89\%) found C (46.28\%) H (3.54\%) N (5.01\%). 
2-Chloro-1-[5-methoxy-1-(phenylsulfonyl)-1H-indol-3-yl]ethanone (12a)

Conditions: room temperature for $1 \mathrm{~h}$; dark brown solid; yield 70\%; mp: $168-169{ }^{\circ} \mathrm{C}$; IR: 1683 (CO), 1448, $1477\left(\mathrm{SO}_{2}\right) \mathrm{cm}^{-1} ;{ }^{1} \mathrm{H}$ NMR (200 MHz, DMSO) $\delta: 3.79\left(\mathrm{~s}, 3 \mathrm{H}, \mathrm{CH}_{3}\right), 5.15\left(\mathrm{~s}, 2 \mathrm{H}, \mathrm{CH}_{2}\right), 7.05$ $(\mathrm{dd}, 1 \mathrm{H}, J=2.6,9.1 \mathrm{~Hz}, \mathrm{H}-6), 7.82-7.58(\mathrm{~m}, 4 \mathrm{H}, \mathrm{ArH}), 7.88(\mathrm{~d}, 1 \mathrm{H}, J=9.1 \mathrm{~Hz}, \mathrm{H}-7), 8.20-8.05(\mathrm{~m}, 2 \mathrm{H}$, ArH), 8.92 (s, 1H, H-2); ${ }^{13}$ C NMR (50 MHz, DMSO- $\left.d_{6}\right) \delta: 47.1$ (t), 55.4 (q), 104.2 (d), 114.0 (d), 115.0 (d), 117.6 (s), 127.1 (dx2), 128.1 (s), 128.4 (s), 130.1 (dx2), 134.9 (d), 135.3 (d), 136.3 (s), 157.2 (s), 187.4 (s). Anal. Calcd. for $\mathrm{C}_{17} \mathrm{H}_{14} \mathrm{ClNO}_{4} \mathrm{~S} \mathrm{C}(56.12 \%) \mathrm{H}(3.88 \%) \mathrm{N}(3.85 \%)$ found $\mathrm{C}(55.91 \%) \mathrm{H}(3.98 \%) \mathrm{N}(4.07 \%)$.

1-[5-Bromo-1-(phenylsulfonyl)-1H-indol-3-yl]-2-chloroethanone (12b)

Conditions: room temperature for $1 \mathrm{~h}$; brown solid; yield 70\%; mp: $168-169^{\circ} \mathrm{C}$; IR: 1689 (CO), 1366, $1442\left(\mathrm{SO}_{2}\right) \mathrm{cm}^{-1} ;{ }^{1} \mathrm{H}$ NMR $\left(200 \mathrm{MHz}\right.$, DMSO- $\left.d_{6}\right) \delta: 5.20\left(\mathrm{~s}, 2 \mathrm{H}, \mathrm{CH}_{2}\right), 7.63-7.75(\mathrm{~m}, 4 \mathrm{H}, \mathrm{H}-6$, ArH), $8.00(\mathrm{~d}, 1 \mathrm{H}, J=8.9 \mathrm{~Hz}, \mathrm{H}-7), 8.17-8.21(\mathrm{~m}, 2 \mathrm{H}, \mathrm{H}-4, \mathrm{ArH}), 8.32(\mathrm{~d}, 1 \mathrm{H}, J=1.8 \mathrm{~Hz}, \mathrm{ArH}), 9.07$ $(\mathrm{s}, 1 \mathrm{H}, \mathrm{H}-2) ;{ }^{13} \mathrm{C}$ NMR $\left(50 \mathrm{MHz}, \mathrm{DMSO}-d_{6}\right) \delta: 47.1$ (t), 115.1 (d), 116.9 (s), 118.0 (s),124.3 (s), 127.2 (dx2), 128.7 (d), 128.8 (d), $130.2(\mathrm{dx2}), 132.8$ (s), 134.5 (d), 135.6 (d), 136.0 (s), 187.3 (s). Anal. Calcd. for $\mathrm{C}_{16} \mathrm{H}_{11} \mathrm{BrClNO}_{3} \mathrm{~S} \mathrm{C}(46.57 \%) \mathrm{H}(2.69 \%) \mathrm{N}(3.39 \%)$ found C (46.35\%) H $(2.87 \%) \mathrm{N}(3.25 \%)$.

2-Chloro-1-[5-fluoro-1-(phenylsulfonyl)-1H-indol-3-yl]ethanone (12c)

Conditions: room temperature for $1 \mathrm{~h}$; light brown; yield $60 \%$; mp: $126-127^{\circ} \mathrm{C}$; IR: 1688 (CO), 1376, $1447\left(\mathrm{SO}_{2}\right) \mathrm{cm}^{-1} ;{ }^{1} \mathrm{H}$ NMR $\left(200 \mathrm{MHz}, \mathrm{DMSO}-d_{6}\right) \delta: 5.16\left(\mathrm{~s}, 2 \mathrm{H}, \mathrm{CH}_{2}\right), 7.33(\mathrm{td}, 1 \mathrm{H}, J=2.7,9.2 \mathrm{~Hz}$, H-6), 7.66 (m, 3H, ArH, H-7), $7.86(\mathrm{dd}, 1 \mathrm{H}, J=9.2,2.6 \mathrm{~Hz}, \mathrm{ArH}), 8.02(\mathrm{dd}, 1 \mathrm{H}, J=9.2,4.3 \mathrm{~Hz}, \mathrm{ArH})$, $8.16(\mathrm{~m}, 2 \mathrm{H}, \mathrm{ArH}), 9.04(\mathrm{~s}, 1 \mathrm{H}, \mathrm{H}-2) ;{ }^{13} \mathrm{C}$ NMR $\left(50 \mathrm{MHz}, \mathrm{DMSO}-d_{6}\right) \delta: 47.1(\mathrm{t}), 107.6\left(\mathrm{~d}, J_{C 4-F}=25.1 \mathrm{~Hz}\right)$, $113.9(\mathrm{~d}), 114.8\left(\mathrm{~d}, J_{C 7-F}=9.6 \mathrm{~Hz}\right), 114.9(\mathrm{~d}), 117.4(\mathrm{~s}), 117.5(\mathrm{~s}), 127.2(\mathrm{dx} 2), 130.2(\mathrm{dx2}), 130.4(\mathrm{~s}), 135.8$ $\left(\mathrm{d}, J_{C 6-F}=21.9 \mathrm{~Hz}\right), 136.1(\mathrm{~s}), 159.2\left(\mathrm{~s}, J_{\mathrm{C} 5-\mathrm{F}}=299.5 \mathrm{~Hz}\right) 187.3(\mathrm{~s})$; Anal. Calcd. for $\mathrm{C}_{16} \mathrm{H}_{11} \mathrm{ClFNO}_{3} \mathrm{~S} \mathrm{C}$ (54.63\%) H (3.15\%) N (3.98\%) found C (54.38\%) H (2.87\%) N (4.22\%).

\subsubsection{Synthesis of 3-(1-Benzenesulfonyl-1H-indol-3-yl)-2-bromoethanone (12d)}

To a stirred solution of 1-[1-(phenylsulfonyl)-1H-indol-3-yl]ethanone 7c $(0.5 \mathrm{~g}, 1.7 \mathrm{mmol})$ in ethanol $(15.0 \mathrm{~mL})$, bromine $(0.1 \mathrm{~mL}, 2 \mathrm{mmol})$ was added dropwise under nitrogen atmosphere. The reaction mixture was heated under reflux for $2 \mathrm{~h}$. After cooling the solvent was evaporated under reduced pressure. The residue was treated with water $(20 \mathrm{~mL})$, made alkaline by adding sodium hydrogen carbonate $(150 \mathrm{mg})$ and extracted with EtOAc $(3 \times 50 \mathrm{~mL})$. The organic phase was dried $\left(\mathrm{Na}_{2} \mathrm{SO}_{4}\right)$, evaporated under reduced pressure and purified by column chromatography using cycloexane/ethyl acetate $95: 5$ as eluent. Yield 70\%; analytical and spectroscopic data were in accordance with those previously reported [34].

\subsubsection{Synthesis of 5-Substituted-3-[2-(naphthalen-2-yl)-1,3-thiazol-4-yl]-1-(protected)-1H-indoles (4a-h)}

A suspension of the proper 3-haloacetyl derivative 11a-d or 12a-d $(0.84 \mathrm{mmol})$ and naphthalene-2-carbothioamide $17(0.16 \mathrm{~g}, 0.84 \mathrm{mmol})$, in anhydrous ethanol $(5.0 \mathrm{~mL})$, was heated under reflux for $30 \mathrm{~min}-6 \mathrm{~h}$ or at $60^{\circ} \mathrm{C}$ for $12 \mathrm{~h}$. The solid formed was filtered, dried, an purified by column chromatography using cycloexane/ethyl acetate as eluent.

5-Methoxy-1-methyl-3-[2-(naphthalen-2-yl)-1,3-thiazol-4-yl]-1H-indole (4a)

Conditions: reflux for $1 \mathrm{~h}$; cycloexane/ethyl acetate 7:3; light yellow solid; yield 95\%; mp: 168-169 ${ }^{\circ} \mathrm{C} ;{ }^{1} \mathrm{H}$ NMR $\left(200 \mathrm{MHz}\right.$, DMSO- $\left.d_{6}\right) \delta: 3.85\left(\mathrm{~s}, 3 \mathrm{H}, \mathrm{CH}_{3}\right), 3.90\left(\mathrm{~s}, 3 \mathrm{H}, \mathrm{CH}_{3}\right), 6.99(\mathrm{dd}, 1 \mathrm{H}, J=2.4$, $\left.8.9 \mathrm{~Hz}, \mathrm{H}-6^{\prime \prime}\right), 7.42\left(\mathrm{~d}, 1 \mathrm{H}, J=8.9 \mathrm{~Hz}, \mathrm{H}-7^{\prime \prime}\right), 7.58-7.63(\mathrm{~m}, 1 \mathrm{H}, \mathrm{ArH}), 7.72\left(\mathrm{~d}, 1 \mathrm{H}, J=2.4 \mathrm{~Hz}, \mathrm{H}-4^{\prime \prime}\right), 7.88$ (s, 1H, H-2"), 7.97-8.02 (m, 3H, ArH), 8.06-8.13 (m, 2H, ArH), 8.21 (dd, 1H, J = 1.7, 8.6 Hz, ArH), 8.61 $(\mathrm{s}, 1 \mathrm{H}, \mathrm{H}-5) ;{ }^{13} \mathrm{C}$ NMR (50 MHz, DMSO-d 6 ) $8: 32.7$ (q), 55.4 (q), 120.2 (d), 109.5 (s), 190.9 (d), 110.0 (s), 111.0 (d), 111.6 (d), 123.6 (d), 125.3 (d), 127.0 (d), 127.1 (d), 127.8 (d), 128.5 (d), 128.9 (d), 129.7 (d), 130.7 
(s), $130.3(\mathrm{~s}), 132.9$ (s), 133.6 (s), 151.7 (s), 154.3 (s), 165.8 (s). Anal. Calcd. for $\mathrm{C}_{23} \mathrm{H}_{18} \mathrm{~N}_{2} \mathrm{OS} \mathrm{C}=\mathrm{C}(74.57 \%)$ $\mathrm{H}(4.90 \%) \mathrm{N}(7.56 \%)$ found C $(74.85 \%) \mathrm{H}(4.63 \%) \mathrm{N}(7.73 \%)$.

5-Bromo-1-methyl-3-[2-(naphthalen-2-yl)-1,3-thiazol-4-yl]-1H-indole (4b)

Conditions: reflux for $1 \mathrm{~h}$; cycloexane/ethyl acetate 7:3; light brown solid; yield 72\%; mp: 124-125 ${ }^{\circ} \mathrm{C} ;{ }^{1} \mathrm{H}$ NMR $\left(200 \mathrm{MHz}, \mathrm{DMSO}-d_{6}\right) \delta: 3.90\left(\mathrm{~s}, 3 \mathrm{H}, \mathrm{CH}_{3}\right), 7.40$ (dd, $\left.1 \mathrm{H}, J=1.8,8.7 \mathrm{~Hz}, \mathrm{H}-6^{\prime \prime}\right)$, 7.50 (d, 1H, J = 8.7, H-7"), 7.60 (m, 2H, ArH), 7.97-8.03 (m, 2H, H-4" , H-2"), 8.08-8.12 (m, 3H, ArH), $8.20(\mathrm{dd}, 1 \mathrm{H}, J=1.8,9.6 \mathrm{~Hz}, \mathrm{ArH}), 8.40(\mathrm{~d}, 1 \mathrm{H}, J=1.8 \mathrm{~Hz} ; \mathrm{ArH}), 8.60(\mathrm{~s}, 1 \mathrm{H}, \mathrm{H}-5) ;{ }^{13} \mathrm{C} \mathrm{NMR}(50 \mathrm{MHz}$, DMSO- $d_{6}$ ) $\delta: 32.9$ (q), 109.6 (s), 111.0 (d), 112.4 (d), 112.9 (s), 112.5 (d), 116.4 (s), 123.5 (d), 124.2 (d), 125.4 (d), 126.5 (s), 127.0 (d), 127.2 (d), 127.8 (d), 128.5 (d), 128.9 (d), 130.6 (d), 132.9 (s), 133.6 (s), 135.7 (s), 150.8 (s), 166.2 (s). Anal. Calcd. for $\mathrm{C}_{22} \mathrm{H}_{15} \mathrm{BrN}_{2} \mathrm{~S} \mathrm{C}(63.01 \%) \mathrm{H}(3.61 \%) \mathrm{N}(6.68 \%)$ found $\mathrm{C}(62.89 \%)$ $\mathrm{H}(3.85 \%) \mathrm{N}(6.44 \%)$.

5-Fluoro-1-methyl-3-[2-(naphthalen-2-yl)-1,3-thiazol-4-yl]-1H-indole (4c)

Conditions: $60^{\circ} \mathrm{C}$ for $12 \mathrm{~h}$; cycloexane/ethyl acetate 7:3; brown solid; yield $48 \%$; mp: 151-152 ${ }^{\circ} \mathrm{C}$; ${ }^{1} \mathrm{H}$ NMR (200 MHz, DMSO- $\left.d_{6}\right)$ 8: $3.90\left(\mathrm{~s}, 3 \mathrm{H}, \mathrm{CH}_{3}\right), 7.15$ (td, $\left.1 \mathrm{H}, J=2.4,9.1 \mathrm{~Hz}, \mathrm{H}-6{ }^{\prime \prime}\right), 7.53-7.65$ (m, 3H, ArH, H-7", H-4"), 7.93 (s, 1H, H-2"), 7.98-8.04 (m, 2H, ArH), 8.07-8.15 (m, 3H, ArH), 8.22 $(\mathrm{dd}, 1 \mathrm{H}, J=1.6,8.6 \mathrm{~Hz}, \mathrm{ArH}), 8.61(\mathrm{~s}, 1 \mathrm{H}, \mathrm{H}-5) ;{ }^{13} \mathrm{C}$ NMR (50 MHz, DMSO- $\left.d_{6}\right) \delta: 32.9$ (q), $105.2(\mathrm{~d}$, $\left.J_{C-44^{\prime \prime}-F}=23.9 \mathrm{~Hz}\right), 109.6(\mathrm{~d}), 110.1(\mathrm{~d}), 110.4(\mathrm{~d}), 111.4(\mathrm{~d}), 111.6(\mathrm{~d}), 123.6$ (d), $125.0(\mathrm{~s}), 125.1$ (s), 125.3 (d), $127.0(\mathrm{~d}), 127.5\left(\mathrm{~d} J_{\mathrm{C}-6^{\prime \prime}-F}=29.4 \mathrm{~Hz}\right), 128.7\left(\mathrm{~d}, J_{\mathrm{C}-7^{\prime \prime}-F}=16.3 \mathrm{~Hz}\right), 131.0(\mathrm{~d}), 130.6$ (s), 132.9 (s), 133.6 (s), 133.8 (s), 151.1 (s), 166.0 (s). Anal. Calcd. for $\mathrm{C}_{22} \mathrm{H}_{15} \mathrm{FN}_{2} \mathrm{~S} \mathrm{C}(73.72 \%) \mathrm{H}(4.22 \%) \mathrm{N}(7.82 \%)$ found C (73.98\%) H (4.56\%) N (7.631\%).

1-Methyl-3-[2-(naphthalen-2-yl)-1,3-thiazol-4-yl]-1H-indole (4d)

Conditions: reflux for $1 \mathrm{~h}$; cycloexane/ethyl acetate 7:3; brown solid; yield 75\%; mp: $174-175{ }^{\circ} \mathrm{C}$; ${ }^{1} \mathrm{H}$ NMR $\left(200 \mathrm{MHz}\right.$, DMSO- $\left.d_{6}\right) \delta: 3.90\left(\mathrm{~s}, 3 \mathrm{H}, \mathrm{CH}_{3}\right), 7.19-7.32(\mathrm{~m}, 2 \mathrm{H}, \mathrm{H}-6$ " , H-7") , 7.52-7.65 (m, 2H, H-4", ArH), 7.88 (s, 1H, H-2"), 7.98-8.15 (m, 4H, ArH), 8.20-8.28 (m, 2H, ArH), 8.61 (s, 1H, H-5); ${ }^{13} \mathrm{C}$ NMR (50 MHz, DMSO- $d_{6}$ ) $\delta: 109.9$ (s), 110.2 (d), 110.3 (d), 120.0 (d), 120.3 (d), 121.7(d), 124.9 (s), 125.3 (d), 126.7 (d), 127.0 (d), 127.1 (d), 127.8 (d), 128.6 (d), 128.9 (d), 129.2 (d), 130.7 (s), 132.9 (s), 133.6 (s), 137.0 (s), 151.6 (s), 165.9 (s). Anal. Calcd. for $\mathrm{C}_{22} \mathrm{H}_{16} \mathrm{~N}_{2} \mathrm{~S} \mathrm{C}(77.62 \%) \mathrm{H}(4.74 \%) \mathrm{N}(8.23 \%)$ found $\mathrm{C}$ (77.45\%) H (4.79\%) N (7.98\%).

5-Methoxy-3-[2-(naphthalen-2-yl)-1,3-thiazol-4-yl]-1-(phenylsulfonyl)-1 $H$-indole (4e)

Conditions: reflux for $1 \mathrm{~h}$; cycloexane/ethyl acetate 9:1; white solid; yield $90 \%$; mp: $168-169^{\circ} \mathrm{C}$; IR: 1451, $1526\left(\mathrm{SO}_{2}\right) \mathrm{cm}^{-1}{ }^{1} \mathrm{H}$ NMR $\left(200 \mathrm{MHz}, \mathrm{DMSO}-d_{6}\right) \delta: 3.89\left(\mathrm{~s}, 3 \mathrm{H}, \mathrm{CH}_{3}\right), 7.06(\mathrm{dd}, 1 \mathrm{H}, J=2.5$, 9.0 Hz, H-6"), 7.56-7.75 (m, 5H, H-7", ArH), 7.82 (d; 1H, J = 2.5 Hz, H-4"), 7.92-8.14 (m, 6H, ArH), 8.23 $(\mathrm{dd}, 1 \mathrm{H}, J=1.7,8.6 \mathrm{~Hz}, \mathrm{ArH}), 8.33\left(\mathrm{~s}, 1 \mathrm{H}, \mathrm{H}-2^{\prime \prime}\right), 8.44(\mathrm{~s}, 1 \mathrm{H}, \mathrm{H}-5), 8.64(\mathrm{~m}, 1 \mathrm{H}, \mathrm{ArH}) ;{ }^{13} \mathrm{C} \mathrm{NMR}(50 \mathrm{MHz}$, DMSO- $d_{6}$ ) $\delta: 55.43$ (q), 104.3 (d), 110.3 (s), 114.1 (d), 114.2 (d), 115.5 (d), 117.6 (s), 123.5 (d), 125.5 (d), 125.6 (d), 126.7 (d), 127.1 (dx2), 127.3 (d), 127.8 (d), 128.6 (d), 128.9 (d), 129.2 (s), 129.9 (dx2), 130.3 (s), 132.9 (s), 133.7 (s), 134.7 (d), 136.7 (s), 148.6 (s), 156.5 (s), 166.8 (s). Anal. Calcd. for $\mathrm{C}_{28} \mathrm{H}_{20} \mathrm{~N}_{2} \mathrm{O}_{3} \mathrm{~S}_{2} \mathrm{C}$ $(67.72 \%) \mathrm{H}(4.06 \%) \mathrm{N}(5.64 \%)$ found C (67.55\%) H (4.23\%) N (5.77\%).

5-Bromo-3-[2-(naphthalen-2-yl)-1,3-thiazol-4-yl]-1-(phenylsulfonyl)- $1 H$-indole (4f)

Conditions: reflux for $6 \mathrm{~h}$; cycloexane/ethyl acetate 8:2; white solid; yield 70\%; mp: $216-217^{\circ} \mathrm{C}$; IR: $1451,1526\left(\mathrm{SO}_{2}\right) \mathrm{cm}^{-1} ;{ }^{1} \mathrm{H}$ NMR (200 MHz, DMSO- $\left.d_{6}\right) \delta:$ 7.57-7.78 (m, 6H, ArH), 7.96-8.04 (m, 2H, ArH), 8.08-8.14 (m, 4H, ArH), 8.20 (dd, $1 \mathrm{H}, J=1.8,8.1 \mathrm{~Hz}, \mathrm{ArH}), 8.38\left(\mathrm{~s}, 1 \mathrm{H}, \mathrm{H}-2^{\prime \prime}\right), 8.52(\mathrm{~d}, 1 \mathrm{H}, J=1.8$, ArH), 8.56 (s, 1H, H-5), 8.62 (s, 1H, ArH); ${ }^{13} \mathrm{C}$ NMR (50 MHz, DMSO-d 6 ) $\delta: 115.3$ (d),116.1 (d), 116.8 (s), 117.0 (s), 123.5 (d), 124.2 (d), 125.7 (d), 126.1 (d), 126.8 (d), 127.1 (dx2), 127.4 (d), 127.8 (d), 128.0 (d), $128.6(\mathrm{~d}), 129.0$ (d), 129.6 (s), $130.0(\mathrm{dx} 2), 130.2(\mathrm{~s}), 132.9$ (s), 133.5 (s), 133.7 (s), 135.0 (d), 136.5 (s), 147.9 
(s), 167.1 (s). Anal. Calcd. for $\mathrm{C}_{27} \mathrm{H}_{17} \mathrm{BrN}_{2} \mathrm{O}_{2} \mathrm{~S}_{2} \mathrm{C}(59.45 \%) \mathrm{H}(3.14 \%) \mathrm{N}(5.14 \%)$ found $\mathrm{C}(59.69 \%) \mathrm{H}$ $(3.34 \%) \mathrm{N}(5.38 \%)$.

5-Fluoro-3-[4-(naphthalen-2-yl)-1,3-thiazol-2-yl]-1-(phenylsulfonyl)-1H-indole (4g)

Conditions: reflux for $2 \mathrm{~h}$; cycloexane/ethyl acetate 8:2; white solid; yield 60\%; mp: 193-194 ${ }^{\circ} \mathrm{C}$; IR: 1447, $1375\left(\mathrm{SO}_{2}\right) \mathrm{cm}^{-1}{ }^{1}{ }^{1} \mathrm{H}$ NMR $\left(200 \mathrm{MHz}, \mathrm{DMSO}-d_{6}\right) \delta: 7.34(\mathrm{td}, J=2.5,9.1 \mathrm{~Hz}, \mathrm{H}-6$ ") $)$ 7.57-7.77 (m, 5H, ArH), 7.97-8.04 (m, 1H, ArH), 8.06-8.17 (m, 6H, ArH ), 8.22 (dd, 1H, J = 1.7, 8.6 Hz, ArH) 8.36 (s, 1H, H-2"), 8.59 (s, 1H, H-5), 8.63 (m, 1H, ArH); ${ }^{13} \mathrm{C}$ NMR (50 MHz, DMSO- $\left.d_{6}\right) \delta: 107.5$ (d, $\left.J_{C 4^{\prime \prime}-F}=25.5 \mathrm{~Hz}\right), 113.0(\mathrm{~d}), 113.6(\mathrm{~d}), 114.8\left(\mathrm{~d}, J_{C 7^{\prime \prime}-F}=9.5 \mathrm{~Hz}\right), 115.7(\mathrm{~d}), 123.5(\mathrm{~d}), 123.6(\mathrm{~d}), 125.7(\mathrm{~s})$, $126.6(\mathrm{~d}), 126.8(\mathrm{dx} 2), 127.0(\mathrm{~d}), 127.6\left(\mathrm{~d}, J_{\mathrm{C6}{ }^{\prime \prime}-F}=21.1 \mathrm{~Hz}\right), 128.6(\mathrm{~d}), 128.9(\mathrm{~d}), 130.0(\mathrm{dx} 2), 131.2(\mathrm{~s}), 132.8$ (s), $133.7(\mathrm{~s}), 134.9$ (s), $135.0(\mathrm{~d}), 136.5$ (s), 148.2 (s), 165.9 (s) 167.0 (s). Anal. Calcd. for $\mathrm{C}_{27} \mathrm{H}_{17} \mathrm{FN}_{2} \mathrm{O}_{2} \mathrm{~S}_{2}$ C (66.92\%) H (3.54\%) N (5.78\%) found C (66.73\%) H (3.31\%) N (5.64\%).

3-[2-(Naphthalen-2-yl)-1,3-thiazol-4-yl]-1-(phenylsulfonyl)-1H-indole (4h)

Conditions: reflux for $30 \mathrm{~min}$; cycloexane/ethyl acetate 9:1;yellow solid; yield 94\%; $\mathrm{mp}$ : 199-200 ${ }^{\circ} \mathrm{C}$; IR: 1447, $1373\left(\mathrm{SO}_{2}\right) \mathrm{cm}^{-1} ;{ }^{1} \mathrm{H}$ NMR $\left(200 \mathrm{MHz}, \mathrm{DMSO}-d_{6}\right) \delta: 7.41-7.52(\mathrm{~m}, 2 \mathrm{H}, \mathrm{ArH})$, 7.57-7.75 (m, 5H, ArH), 7.98-8.17 (m, 6H, ArH), 8.23 (dd, 1H, J = 1.8, 8.6 Hz, ArH), $8.33(\mathrm{~s}, 1 \mathrm{H}, \mathrm{H}-2 ")$, $8.39(\mathrm{~m}, 1 \mathrm{H}, \mathrm{ArH}), 8.50(\mathrm{~s} ; 1 \mathrm{H}, \mathrm{H}-5), 8.65(\mathrm{~m}, 1 \mathrm{H}, \mathrm{ArH}) ;{ }^{13} \mathrm{C}$ NMR (50 MHz, DMSO- $\left.d_{6}\right) \delta: 113.2(\mathrm{~s})$, 113.3 (d), 115.6 (d), 117.6 (s), 121.9 (d), 123.6 (d), 124.2 (d), 124.8 (d), 125.4 (d), 125.7 (d), 126.8 (dx2), 127.0 (d), 127.3 (d), 127.8 (d), 128.6 (d), 128.9 (d), 129.9 (dx2), 130.2 (s), 132.9 (s), 133.47 (s), 134.6 (s), 134.8 (d), 136.7 (s), 148.6 (s), 166.9 (s). Anal. Calcd. for $\mathrm{C}_{27} \mathrm{H}_{18} \mathrm{~N}_{2} \mathrm{O}_{2} \mathrm{~S}_{2} \mathrm{C}(69.50 \%) \mathrm{H}(3.89 \%) \mathrm{N}(6.00 \%)$ found C (69.35\%) H (3.98\%) N (5.73\%).

\subsubsection{Synthesis of 5-Substituted-3-[2-(naphthalen-2-yl)-1,3-thiazol-4-yl]-1H-indoles (4i-1)}

To a suspension of the proper 3-[2-(naphthalen-2-yl)-1,3-thiazol-4-yl]-1-(phenylsulfonyl)-1H-indole $4 \mathbf{e}-\mathbf{h}(0.3 \mathrm{mmol})$ in ethanol $(6.5 \mathrm{~mL})$, a solution of sodium hydroxide $(1.74 \mathrm{mmol}, 0.07 \mathrm{~g})$ in water $(4.0 \mathrm{~mL})$ was added. The reaction mixture was heated under reflux for 5-6 h. The solvent was evaporated under reduced pressure, and the resulting mixture neutralized with $\mathrm{HCl} 3 \mathrm{~N}(2.0 \mathrm{~mL})$ and extracted in ethyl acetate $(3 \times 50 \mathrm{~mL})$. The organic phase was dried $\left(\mathrm{Na}_{2} \mathrm{SO}_{4}\right)$, evaporated under reduced pressure and purified by column chromatography using cycloexane/ethyl acetate 7:3 as eluent.

5-Methoxy-3-[4-(naphthalen-2-yl)-1,3-thiazol-2-yl]-1H-indole (4i)

Conditions: reflux for $6 \mathrm{~h}$; yellow solid; yield 50\%; mp: $175-176{ }^{\circ} \mathrm{C}$; IR: $3378(\mathrm{NH}) \mathrm{cm}^{-1} ;{ }^{1} \mathrm{H} \mathrm{NMR}$ $\left(200 \mathrm{MHz}, \mathrm{DMSO}-d_{6}\right) \delta: 3.90\left(\mathrm{~s}, 3 \mathrm{H}, \mathrm{CH}_{3}\right), 6.85\left(\mathrm{dd}, 1 \mathrm{H}, J=2.3,8.8 \mathrm{~Hz}, \mathrm{H}-6^{\prime \prime}\right), 7.39(\mathrm{~d}, 1 \mathrm{H}, J=8.8 \mathrm{~Hz}$, H-7"), 7.58-7.63 (m, 2H, ArH), $7.72\left(\mathrm{~d}, 1 \mathrm{H}, J=2.3 \mathrm{~Hz}, \mathrm{H}-4^{\prime \prime}\right), 7.89\left(\mathrm{~s}, 1 \mathrm{H}, \mathrm{H}-\mathrm{2}^{\prime \prime}\right), 7.98-8.01(\mathrm{~m}, 2 \mathrm{H}$, ArH), 8.07-8.14 (m, 2H, ArH), 8.23 (dd, $1 \mathrm{H}, J=1.5,8.6 \mathrm{~Hz}, \mathrm{ArH}), 8.62(\mathrm{~s}, 1 \mathrm{H}, \mathrm{H}-5), 11.34(\mathrm{~s}, 1 \mathrm{H}, \mathrm{NH})$; ${ }^{13} \mathrm{C}$ NMR (50 MHz, DMSO-d $\left.d_{6}\right) \delta: 55.4$ (q), 102.0 (d), 109.9 (d), 110.6 (s), 111.7 (d), 112.5 (d), 125.6 (s), 123.6 (d), 125.0 (d), 125.3 (d), 127.0 (d), 127.1 (d), 127.8 (d), 128.5 (d), 128.9 (d), 130.8 (s), 131.7 (s), 132.9 (s), 133.6 (s), 152.2 (s), 154.0 (s), 165.7 (s). Anal. Calcd. for $\mathrm{C}_{22} \mathrm{H}_{16} \mathrm{~N}_{2} \mathrm{OS} \mathrm{C}(74.13 \%) \mathrm{H}(4.52 \%) \mathrm{N}(7.86 \%)$ found C (73.88\%) H (4.71\%) N (8.03\%).

5-Bromo-3-[2-(naphthalen-2-yl)-1,3-thiazol-4-yl]-1H-indole (4j)

Conditions: reflux for $6 \mathrm{~h}$; yellow solid; yield $68 \%$; mp: $265-266{ }^{\circ} \mathrm{C}$; IR: $3608(\mathrm{NH}) \mathrm{cm}^{-1} ;{ }^{1} \mathrm{H}$ NMR $\left(200 \mathrm{MHz}, \mathrm{DMSO}-d_{6}\right) \delta: 7.31$ (dd, 1H, $\left.J=1.9,8.6 \mathrm{~Hz}, \mathrm{H}-6^{\prime \prime}\right), 7.46-7.50\left(\mathrm{~m}, 1 \mathrm{H}, \mathrm{H}-7^{\prime \prime}\right), 7.59-7.64(\mathrm{~m}, 2 \mathrm{H}$, ArH), 7.95 (s, 1H, H-2"), 7.98-8.03 (m, 1H, ArH), 8.08-8.13 (m, 3H, ArH), $8.22(\mathrm{dd}, 1 \mathrm{H}, J=1.8,8.9 \mathrm{~Hz}$, $\mathrm{ArH}), 8.40(\mathrm{~d}, 1 \mathrm{H}, J=1.8 \mathrm{~Hz}, \mathrm{ArH}), 8.60(\mathrm{~s}, 1 \mathrm{H}, \mathrm{H}-5), 11.41(\mathrm{~s}, 1 \mathrm{H}, \mathrm{NH}) ;{ }^{13} \mathrm{C}$ NMR (50 MHz, DMSO- $\left.d_{6}\right)$ $\delta: 110.8$ (d), 110.9 (d), 122.3 (d), 123.5 (d), 124.12 (d), 125.4 (d), 126.9 (d), 127.0 (d), 127.2 (d), 127.8 (d), $128.5(\mathrm{~d}), 128.9$ (d), 130.7 (s), 132.9 (s), $133.6(\mathrm{~s}), 135.5(\mathrm{~s}), 141.8(\mathrm{~s}), 151.4(\mathrm{~s}), 154.2(\mathrm{~s}), 161.6(\mathrm{~s}), 166.0(\mathrm{~s})$. Anal. Calcd. for $\mathrm{C}_{21} \mathrm{H}_{13} \mathrm{BrN}_{2} \mathrm{~S} \mathrm{C}(62.23 \%) \mathrm{H}(3.23 \%) \mathrm{N}(6.91 \%)$ found C $(62.48 \%) \mathrm{H}(3.55 \%) \mathrm{N}(6.75 \%)$ 
5-Fluoro-3-[4-(naphthalen-2-yl)-1,3-thiazol-2-yl]-1H-indole (4k)

Conditions: reflux for $5 \mathrm{~h}$; white solid; yield $75 \%$; mp: $227-228^{\circ} \mathrm{C}$; IR: $3124(\mathrm{NH}) \mathrm{cm}^{-1} ;{ }^{1} \mathrm{H}$ NMR $\left(200 \mathrm{MHz}, \mathrm{DMSO}-d_{6}\right) \delta: 7.06\left(\mathrm{td}, 1 \mathrm{H}, J=2.5,9.2 \mathrm{~Hz}, \mathrm{H}-6^{\prime \prime}\right), 7.49(\mathrm{dd}, 1 \mathrm{H}, J=4.7,8.9 \mathrm{~Hz}, \mathrm{ArH}), 7.60(\mathrm{~m}$, 2H, ArH), 7.95 (s, 1H, H-2"), 7.98-8.14 (m, 5H, ArH), 8.24 (dd, 1H, J = 1.7, 7.8 Hz, ArH), $8.92(\mathrm{~s}, 1 \mathrm{H}$, H-5), 11.62 (s, 1H, NH); ${ }^{13}$ C NMR (50 MHz, DMSO- $\left.d_{6}\right) \delta: 105.0\left(\mathrm{~d}, J_{C 4^{\prime \prime}-F}=24.3 \mathrm{~Hz}\right), 109.6$ (d), 110.2 $\left(\mathrm{d}, J_{\mathrm{C6}{ }^{\prime \prime}-F}=24.3 \mathrm{~Hz}\right) 111.0(\mathrm{~s}), 111.1(\mathrm{~s}), 112.8(\mathrm{~d}), 124.7(\mathrm{~s}), 124.9(\mathrm{~s}), 123.6(\mathrm{~d}), 125.3(\mathrm{~d}), 126.9(\mathrm{~s}), 127.0$ $\left(\mathrm{d}, J_{C 7^{\prime \prime}-F}=3.3 \mathrm{~Hz}\right),(\mathrm{d}), 127.2(\mathrm{~d}), 127.8(\mathrm{~d}), 128.6(\mathrm{~d}), 128.8(\mathrm{~d}), 130.7(\mathrm{~s}), 132.9(\mathrm{~s}), 133.3(\mathrm{~s}), 151.6$ (s), 166.0 (s). Anal. Calcd. for $\mathrm{C}_{21} \mathrm{H}_{13} \mathrm{FN}_{2} \mathrm{~S}_{2} \mathrm{C}(73.23 \%) \mathrm{H}(3.80 \%) \mathrm{N}(8.13 \%)$ found $\mathrm{C}(72.91 \%) \mathrm{H}(4.05 \%)$ $\mathrm{N}(8.44 \%)$

3-[2-(Naphthalen-2-yl)-1,3-thiazol-4-yl]-1H-indole (41)

Conditions: reflux for $5 \mathrm{~h}$; light yellow solid; yield 80\%; mp: $260-261{ }^{\circ} \mathrm{C}$; IR: $2998(\mathrm{NH}) \mathrm{cm}^{-1}$; ${ }^{1} \mathrm{H}$ NMR (200 MHz, DMSO- $\left.d_{6}\right)$ 8: 7.18-7.22 (m, 2H, ArH), 7.47-7.52 (m, 1H, ArH), 7.58-7.65 (m, 2H, ArH), 7.90 (s, 1H, H-2"), 7.98-8.16 (m, 4H, ArH), 8.21-8.28 (m, 2H, ArH), 8.62 (s, 1H, H-5), 11.50 (s, 1H, $\mathrm{NH}) ;{ }^{13} \mathrm{C}$ NMR (50 MHz, DMSO- $d_{6}$ ) $\delta: 110.2$ (d), 110.8 (s), 111.9 (d), 119.8 (d), 120.2 (d), 121.6 (d), 123.7 (d), 124.6 (s), 125.0 (d), 125.3 (d), 127.0 (d), 127.1 (d), 127.8 (d), 128.6 (d), 128.9 (d), 130.7 (s), 132.9 (s), 133.6 (s), 136.3 (s), 152.1 (s), 165.8 (s). Anal. Calcd. for $\mathrm{C}_{21} \mathrm{H}_{14} \mathrm{~N}_{2} \mathrm{~S} \mathrm{C}(77.27 \%) \mathrm{H}(4.32 \%) \mathrm{N}(8.58 \%)$ found C $(77.48 \%) \mathrm{H}(4.25 \%) \mathrm{N}(8.85 \%)$.

\subsubsection{Synthesis of 3-[2-(Naphthalen-2-yl)-1,3-thiazol-4-yl]-1H-pyrrolo[2,3-b]pyridines (5a-d)}

To a suspension of naphthalene-2-carbothioamide $17(0.07 \mathrm{~g}, 0.4 \mathrm{mmol})$ in anhydrous ethanol $(15.0 \mathrm{~mL})$, the proper 3-bromo-acetyl-pyrrolo[2,3-b]pyridine $\mathbf{1 5} \mathbf{a}, \mathbf{b}$ or $\mathbf{1 6} \mathbf{a}, \mathbf{b}(0.4 \mathrm{mmol})$ was added. The resulting mixture was heated under reflux for 5-6 h. After cooling, the precipitate formed was filtered off and recrystallized from ethanol.

1-Methyl-3-[2-(naphthalen-2-yl)-1,3-thiazol-4-yl]-1H-pyrrolo[2,3-b]pyridine (5a)

Conditions: reflux for $5 \mathrm{~h}$; yellow solid; yield: $75 \%$; mp: $294-295^{\circ} \mathrm{C} ;{ }^{1} \mathrm{H} \mathrm{NMR}\left(200 \mathrm{MHz}\right.$, DMSO- $\left.d_{6}\right)$

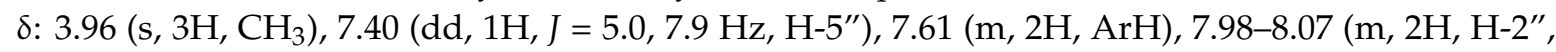
ArH), 8.11-8.15 (m, 2H, ArH), $8.22(\mathrm{dd}, 1 \mathrm{H}, J=1.7,8.6 \mathrm{~Hz}, \mathrm{ArH}), 8.32(\mathrm{~s}, 1 \mathrm{H}, \mathrm{H}-5), 8.46(\mathrm{dd}, 1 \mathrm{H}, J=1.3$, $\left.5.0 \mathrm{~Hz}, \mathrm{H}-6^{\prime \prime}\right), 8.63(\mathrm{~m}, 1 \mathrm{H}, \mathrm{ArH}), 8.84\left(\mathrm{dd}, 1 \mathrm{H}, J=1.3,7.9 \mathrm{~Hz}, \mathrm{H}-4^{\prime \prime}\right) ;{ }^{13} \mathrm{C}$ NMR (50 MHz, DMSO- $\left.d_{6}\right) \delta$ : 31.6 (q), 109.1 (s), 111.7 (d), 116.3 (d), 118.7 (s), 123.6 (d), 125.4 (d), 127.0 (d), 127.2 (d), 127.8 (d), 128.6 (d), 128.9 (d), 129.7 (d), 130.4 (s), 131.3 (d), 132.9 (s), 133.6 (s), 140.8 (d), 145.3 (s), 150.3 (s), 166.5 (s). Anal. Calcd per $\mathrm{C}_{21} \mathrm{H}_{15} \mathrm{~N}_{3} \mathrm{~S}$ : C (73.87\%) H $(4.43 \%) \mathrm{N}(12.31 \%)$ found: C $(73.62 \%) \mathrm{H}(4.67 \%)$; $\mathrm{N}(12.60 \%)$.

5-Bromo-1-methyl-3-[2-(naphthalen-2-yl)-1,3-thiazol-4-yl]-1H-pyrrolo[2,3-b]pyridine (5b)

Conditions: reflux for $4 \mathrm{~h}$; yellow solid; yield: $55 \%$; mp $252-253{ }^{\circ} \mathrm{C} ;{ }^{1} \mathrm{H}$ NMR $\left(200 \mathrm{MHz}\right.$, DMSO- $\left.d_{6}\right)$ $\delta: 3.90\left(\mathrm{~s}, 3 \mathrm{H}, \mathrm{CH}_{3}\right), 7.58-8.63(\mathrm{~m}, 2 \mathrm{H}, \mathrm{ArH}), 7.96-8.01(\mathrm{~m}, 1 \mathrm{H}, \mathrm{ArH}), 8.05-8.12\left(\mathrm{~m}, 3 \mathrm{H}, \mathrm{H}-2^{\prime \prime}, \mathrm{ArH}\right), 8.18$ $(\mathrm{dd}, 1 \mathrm{H}, J=1.7,8.4 \mathrm{~Hz}, \mathrm{ArH}), 8.28(\mathrm{~s}, 1 \mathrm{H}, \mathrm{H}-5), 8.42(\mathrm{~d}, 1 \mathrm{H}, J=2.1 \mathrm{~Hz}, \mathrm{ArH}), 8.58-8.61(\mathrm{~m}, 1 \mathrm{H}, \mathrm{ArH})$, $8.78(\mathrm{~d}, 1 \mathrm{H}, J=2.1 \mathrm{~Hz}, \mathrm{ArH}) ;{ }^{13} \mathrm{C}$ NMR $\left(50 \mathrm{MHz}, \mathrm{DMSO}-d_{6}\right) \delta: 31.2(\mathrm{q}), 108.2(\mathrm{~s}), 111.7(\mathrm{~s}), 111.8(\mathrm{~d})$, 118.8 (s), 123.5 (d), 125.5 (d), 127.0 (d), 127.2 (d), 127.7 (d), 128.5 (d), 128.9 (d), 130.4 (d), 130.5 (s), 130.6 (d), 132.9 (s), 133.6 (s), 143.1 (d), 146.0 (s), 150.0 (s), 166.4 (s). Anal. Calcd per $\mathrm{C}_{21} \mathrm{H}_{14} \mathrm{BrN}_{3} \mathrm{~S}: \mathrm{C}(60.01 \%)$ $\mathrm{H}(3.36 \%) \mathrm{N}(10.00 \%)$ found: C $(59.85 \%) \mathrm{H}(3.60 \%) \mathrm{N}(10.15 \%)$.

3-[2-(Naphthalen-2-yl)-1,3-thiazol-4-yl]-1H-pyrrolo[2,3-b]pyridine (5c)

Conditions: reflux for $4 \mathrm{~h}$; light brown solid; yield: 80\%; mp: 277-278 ${ }^{\circ} \mathrm{C}$; IR: $3126(\mathrm{NH}) \mathrm{cm}^{-1}$; ${ }^{1} \mathrm{H}$ NMR (200 MHz, DMSO- $\left.d_{6}\right)$ 8: 7.35-7.43 (m, 1H, ArH), 7.59-7.65 (m, 2H, ArH), 7.99-8.04 (m, 1H, $\mathrm{Ar}), 8.07$ (s, 1H, H-2"), 8.12-8.18 (m, 2H, H-5, ArH), 8.21-8.34 (m, 2H, ArH), 8.41-8.44(m, 1H, ArH), 8.63 $(\mathrm{d}, 1 \mathrm{H}, J=9.5 \mathrm{~Hz}, \mathrm{ArH}), 8.88(\mathrm{t}, 1 \mathrm{H}, J=7.7 \mathrm{~Hz}, \mathrm{ArH}), 12.40(\mathrm{bs}, 1 \mathrm{H}, \mathrm{NH})$; Anal. Calcd per $\mathrm{C}_{20} \mathrm{H}_{13} \mathrm{~N}_{3} \mathrm{~S}$ : C (73.37\%) H (4.00\%) N 12.83 found C (73.39\%) H (4.11\%) N (12.65\%). 
5-Bromo-3-[2-(naphthalen-2-yl)-1,3-thiazol-4-yl]-1H-pyrrolo[2,3-b]pyridine (5d)

Conditions: reflux for $4 \mathrm{~h}$; white solid; yield: 85\%; mp 300-301 ${ }^{\circ} \mathrm{C}$; IR: 2906 (NH) cm ${ }^{-1} ;{ }^{1} \mathrm{H} \mathrm{NMR}$ (200 MHz, DMSO- $\left.d_{6}\right) \delta:$ 7.62-7.67 (m, 2H, ArH), 7.58-8.03 (m, 1H, ArH), 8.09-8.13 (m, 3H, H-2" , ArH), 8.20-8.25 (m, 2H, H-5, ArH), 8.39 (bs, 1H, ArH), 8.62 (bs, 1H, Ar), 8.82 (bs, 1H, Ar), 12.30 (bs, 1H, $\mathrm{NH})$. Anal. Calcd per $\mathrm{C}_{20} \mathrm{H}_{12} \mathrm{BrN}_{3} \mathrm{~S}: \mathrm{C}(59.12 \%) \mathrm{H}(2.98 \%) \mathrm{N}(10.34 \%)$ found C (59.29\%) H (3.15\%) $\mathrm{N}(10.71 \%)$.

\subsubsection{Synthesis of 3-[4-(Naphthalen-2-yl)-1,3-thiazol-2-yl]-1H-indoles (6a-h)}

To a solution of the proper indolo-3-carbothioamide 22d, 23a-d, 24a-c $(0.91 \mathrm{mmol})$ in dimethylformamide $(6.0 \mathrm{~mL})$, naphthalene-2-acetylbromide $25(0.23 \mathrm{~g}, 0.91 \mathrm{mmol})$ was added. The resulting reaction mixture was heated for $3-6 \mathrm{~h}$ at $60^{\circ} \mathrm{C}$ or for $24 \mathrm{~h}$ at reflux. After reaction completion, monitored by TLC, water $(12.0 \mathrm{~mL})$ was added and the formed precipitate was filtered off. The crude obtained was then purified by column chromatography using cycloexane/ethyl acetate 7:3 as eluent.

5-Methoxy-1-methyl-3-[4-(naphthalen-2-yl)-1,3-thiazol-2-yl]-1H-indole (6a)

Conditions: $60{ }^{\circ} \mathrm{C}$ for $6 \mathrm{~h}$; brown solid; yield $98 \%$; mp: $126-127^{\circ} \mathrm{C}$; cycloexane/ethyl acetate 95:5; ${ }^{1} \mathrm{H}$ NMR $\left(200 \mathrm{MHz}, \mathrm{DMSO}-d_{6}\right) \delta: 3.88\left(\mathrm{~s}, 3 \mathrm{H}, \mathrm{CH}_{3}\right), 3.94\left(\mathrm{~s}, 3 \mathrm{H}, \mathrm{CH}_{3}\right), 6.97(\mathrm{dd}, 1 \mathrm{H}, J=2.5,8.9 \mathrm{~Hz}$, H-6"), 7.47-7.58 (m, 3H, ArH), 7.93-8.05 (m, 4H, ArH), 8.08 (s, 1H, H-2"), 8.18 (s, 1H, H-5), 8.22 (dd, $1 \mathrm{H}, J=1.6,8.6 \mathrm{~Hz}, \mathrm{ArH}), 8.66(\mathrm{~s}, 1 \mathrm{H}, \mathrm{ArH}) ;{ }^{13} \mathrm{C} \mathrm{NMR}\left(50 \mathrm{MHz}, \mathrm{DMSO}-d_{6}\right) \delta: 33.0$ (q), 55.2 (q), 102.3 (d), 109.2 (s), 110.9 (d), 111.5 (d), 112.3(d), 124.3 (d), 124.6 (d), 125.2 (d), 126.1 (s), 126.6 (d), 127.6 (d), 128.2 (d), $128.3(\mathrm{~d}), 130.9$ (d), 131.9 (s), 132.2 (s), 132.6 (s), 133.2 (s), 153.7 (s), 155.0 (s), 162.7 (s). Anal. Calcd. for $\mathrm{C}_{23} \mathrm{H}_{18} \mathrm{~N}_{2} \mathrm{OS} \mathrm{C}(74.57 \%) \mathrm{H}(4.90 \%) \mathrm{N}(7.56 \%)$ found C (74.25\%) H (5.15\%) N (7.37\%).

5-Bromo-1-methyl-3-[4-(naphthalen-2-yl)-1,3-thiazol-2-yl]-1H-indole (6b)

Conditions: $60^{\circ} \mathrm{C}$ for $6 \mathrm{~h}$; cycloexane/ethyl acetate 9:1; orange solid; yield $98 \%$; mp: 182-183 ${ }^{\circ} \mathrm{C}$; ${ }^{1} \mathrm{H}$ NMR $\left(200 \mathrm{MHz}\right.$, DMSO- $\left.d_{6}\right) \delta: 3.90\left(\mathrm{~s}, 3 \mathrm{H}, \mathrm{CH}_{3}\right), 7.45(\mathrm{dd}, 1 \mathrm{H}, J=1.9,8.8 \mathrm{~Hz}, \mathrm{H}-6 ")$ ) 7.51-7.61 (m, $3 \mathrm{H}, \mathrm{ArH}), 7.95(\mathrm{~d}, 1 \mathrm{H}, J=2.8 \mathrm{~Hz}, \mathrm{ArH}), 7.98-8.06(\mathrm{~m}, 2 \mathrm{H}, \mathrm{ArH}), 8.12\left(\mathrm{~s}, 1 \mathrm{H}, \mathrm{H}-2^{\prime \prime}\right), 8.20$ (dd, 1H, J = 1.4, $8.6 \mathrm{~Hz}, \mathrm{ArH}), 8.29$ (s, $1 \mathrm{H}, \mathrm{H}-5), 8.54(\mathrm{~d}, 1 \mathrm{H}, J=1.7 \mathrm{~Hz}, \mathrm{ArH}), 8.61(\mathrm{~s}, 1 \mathrm{H}, \mathrm{ArH}) ;{ }^{13} \mathrm{C} \mathrm{NMR}(50 \mathrm{MHz}$, DMSO-d 6 ) $\delta: 33.1$ (q), 109.0 (s), 111.6 (d), 112.9 (d), 113.9 (s), 122.7 (d), 124.3 (d), 124.6 (d), 125.0 (d), 126.1(s), 126.2 (d), 126.6 (d), 127.7 (d), 128.1 (d), 128.4 (d), 131.7 (s), 132.1 (d), 132.6 (s), 133.1 (s), 135.8 (s), 154.0 (s), 162.0 (s). Anal. Calcd. for $\mathrm{C}_{22} \mathrm{H}_{15} \mathrm{BrN}_{2} \mathrm{~S} \mathrm{C}(63.01 \%) \mathrm{H}(3.61 \%) \mathrm{N}(6.68 \%)$ found $\mathrm{C}(63.36 \%) \mathrm{H}$ $(3.41 \%) \mathrm{N}(6.85 \%)$.

5-Fluoro-1-methyl-3-[4-(naphthalen-2-yl)-1,3-thiazol-2-yl]-1H-indole (6c)

Conditions: $60^{\circ} \mathrm{C}$ for $6 \mathrm{~h}$; cycloexane/ethyl acetate 8:2; orange solid; yield 75\%; mp: $182-183{ }^{\circ} \mathrm{C}$; ${ }^{1} \mathrm{H}$ NMR (200 MHz, DMSO- $\left.d_{6}\right) \delta: 3.91\left(\mathrm{~s}, 3 \mathrm{H}, \mathrm{CH}_{3}\right), 7.20(\mathrm{dt}, \mathrm{J}=2.6,9.1, \mathrm{H}-6 "), 7.50-7.65(\mathrm{~m}, 3 \mathrm{H}$, ), 7.93-8.14 (m, 5H, H-2", ArH), 8.22 (d, 1H, J = 1.7, 8.6 Hz, ArH), 8.31 (s, 1H, H-5), 8.63 (s, 1H, ArH); ${ }^{13} \mathrm{C}$ NMR $\left(50 \mathrm{MHz}, \mathrm{DMSO}-d_{6}\right) \delta: 105.4\left(\mathrm{~d}, J_{\mathrm{C}{ }^{\prime \prime}-F}=24.7 \mathrm{~Hz}\right), 109.5(\mathrm{~s}), 110.7\left(\mathrm{~d}, J_{\mathrm{C} 6^{\prime \prime}-F}=26.0 \mathrm{~Hz}\right), 112.0(\mathrm{~d})$, 111.0 (d), 112.1 (d), 124.3 (d), 124.3 (s), 124.6 (d), 126.1 (d), 126.5 (d), 127.6 (d), 128.3 (d, $\left.J_{C 7^{\prime \prime}-F}=3.8 \mathrm{~Hz}\right)$, 131.7 (s), 132.6 (s), 133.2 (s), 133.4 (d), 133.8 (s), 154.0 (s), 162.3 (s) Anal. Calcd. for $\mathrm{C}_{22} \mathrm{H}_{15} \mathrm{FN}_{2} \mathrm{~S} \mathrm{C}$ (73.72\%) H (4.22\%) N (7.82\%) found C (73.36\%) H (4.45\%) N (7.95\%).

1-Methyl-3-[4-(naphthalen-2-yl)-1,3-thiazol-2-yl]-1H-indole (6d)

Conditions: reflux for $24 \mathrm{~h}$; cycloexane/ethyl acetate 9:1; orange solid; yield 99\%; mp: 166-167 ${ }^{\circ} \mathrm{C}$; ${ }^{1} \mathrm{H}$ NMR $\left(200 \mathrm{MHz}, \mathrm{DMSO}-d_{6}\right) \delta: 3.91\left(\mathrm{~s}, 3 \mathrm{H}, \mathrm{CH}_{3}\right), 7.30-7.38(\mathrm{~m}, 2 \mathrm{H}, \mathrm{ArH}), 7.53-7.61(\mathrm{~m}, 3 \mathrm{H}, \mathrm{ArH})$, 7.93-8.08 (m, 3H, ArH ), 8.10 (s, 1H, H-2"), 8.20 (d, 1H, $J=1.4$ Hz, ArH), 8.25 (s, 1H, H-5), 8.39-8.44 (m, $1 \mathrm{H}, \mathrm{ArH}), 8.66(\mathrm{~s}, 1 \mathrm{H}, \mathrm{ArH}) ;{ }^{13} \mathrm{C}$ NMR $\left(50 \mathrm{MHz}, \mathrm{DMSO}-d_{6}\right) \delta: 32.8$ (q), 109.5 (s), 110.6 (d), 110.7 (s), 111.2 (d), 120.6 (d), 121.1 (d), 122.5 (d), 124.4 (d), 124.6 (d), 126.1 (d), 126.5 (d), 127.6 (d), 128.2 (d), 128.3 
(d), 130.7 (d), 131.8 (s), 132.6 (s), 133.2 (s), 137.1 (s), 153.9 (s), 162.6 (s). Anal. Calcd per $\mathrm{C}_{22} \mathrm{H}_{16} \mathrm{~N}_{2} \mathrm{~S}: \mathrm{C}$ (77.62\%) H (4.74\%) N (8.23\%) found C (77.45\%) H (4.39\%) N (8.05\%).

5-Methoxy-3-[4-(naphthalen-2-yl)-1,3-thiazol-2-yl]-1H-indole (6e)

Conditions: $60{ }^{\circ} \mathrm{C}$ for $6 \mathrm{~h}$; cycloexane/ethyl acetate 9:1; light brown solid; yield 48\%; mp: 145-146 ${ }^{\circ} \mathrm{C}$; IR: 3019 (NH) cm ${ }^{-1}$; ${ }^{1} \mathrm{H}$ NMR $\left(200 \mathrm{MHz}, \mathrm{DMSO}-d_{6}\right) \delta: 3.94\left(\mathrm{~s}, 3 \mathrm{H}, \mathrm{CH}_{3}\right), 6.92(\mathrm{dd}, 1 \mathrm{H}$, $\left.J=2.5,8.8 \mathrm{~Hz}, \mathrm{H}-6^{\prime \prime}\right), 7.43$ (d, 1H, J = 8.8 Hz, H-7"), 7.53-7.58 (m, 2H, ArH), $7.94(\mathrm{~d}, 1 \mathrm{H}, J=2.5 \mathrm{~Hz}$, H-4"), 7.98-8.05 (m, 3H, H-2" , ArH), 8.08 (s, 1H, H-5), 8.15 (d, 1H, J = 2.8 Hz, ArH), 8.22 (dd, 1H, J = 1.5, $8.6 \mathrm{~Hz}, \mathrm{ArH}), 8.66(\mathrm{~s}, 1 \mathrm{H}, \mathrm{ArH}), 11.70(\mathrm{~s}, 1 \mathrm{H} ; \mathrm{NH}) ;{ }^{13} \mathrm{C}$ NMR $\left(50 \mathrm{MHz}, \mathrm{DMSO}-d_{6}\right) \delta: 55.2(\mathrm{q}), 102.1$ (d), 110.3 (s), 110.9 (d), 112.4 (d), 113.0 (d), 124.3 (d), 124.6 (d), 124.9 (s), 126.1 (d), 126.6 (d), 127.2 (d), 127.6 (d), 128.2 (d), 128.3 (d), 131.6 (s), 131.9 (s), 132.6 (s), 133.2 (s), 153.7 (s), 154.7 (s), 163.1 (s). Anal. Calcd. for $\mathrm{C}_{22} \mathrm{H}_{16} \mathrm{~N}_{2} \mathrm{OSC}$ C (74.13\%) H (4.52\%) N (7.86\%) found C (74.44\%) H (4.87\%) N (7.66\%).

5-Bromo-3-[4-(naphthalen-2-yl)-1,3-thiazol-2-yl]-1H-indole (6f)

Conditions: $60{ }^{\circ} \mathrm{C}$ for $3 \mathrm{~h}$; cycloexane/ethyl acetate 8:2; dark brown solid; yield 75\%; $\mathrm{mp}$ : 224-225 ${ }^{\circ} \mathrm{C}$; IR $3202(\mathrm{NH}) \mathrm{cm}^{-1} ;{ }^{1} \mathrm{H}$ NMR $\left(200 \mathrm{MHz}, \mathrm{DMSO}-d_{6}\right) \delta: 7.40\left(\mathrm{dd}, 1 \mathrm{H}, J=1.8,8.7 \mathrm{~Hz}, \mathrm{H}-6^{\prime \prime}\right)$, 7.49 (s, 1H, H-4"), 7.54-7.62 (m, 2H, H-7", ArH), 7.94-8.06 (m, 3H, H-2" , ArH ), 8.12 (s, 1H, H-5), 8.21 $(\mathrm{dd}, 1 \mathrm{H}, J=1.4,8.6 \mathrm{~Hz}, \mathrm{ArH}), 8.28(\mathrm{~d}, 1 \mathrm{H}, J=2.8 \mathrm{~Hz}, \mathrm{ArH}), 8.55(\mathrm{~d}, 1 \mathrm{H}, J=1.4 \mathrm{~Hz}, \mathrm{ArH}), 8.62(\mathrm{~s}, 1 \mathrm{H}$, ArH), 12.02 (s, $1 \mathrm{H}, \mathrm{NH}) ;{ }^{13} \mathrm{C}$ NMR (50 MHz, DMSO- $d_{6}$ ) $\delta: 110.1$ (s), 111.6 (d), 113.4 (s), 114.3 (d), 122.6 (d), 124.3 (d), 124.6 (d), 125.1 (d), 126.0 (s), 126.2 (d), 126.6 (d), 127.7 (d), 128.2 (d), 128.3 (d), 128.4 (d), 131.8 (s), 132.6 (s), 133.2 (s), 135.3 (s), 153.9 (s), 162.4 (s). Anal. Calcd. for $\mathrm{C}_{21} \mathrm{H}_{13} \mathrm{BrN}_{2} \mathrm{~S} \mathrm{C}(62.23 \%) \mathrm{H}$ (3.23\%) N (6.91\%) found C (62.38\%) H (3.11\%) N (7.23\%).

\section{5-Fluoro-3-[4-(naphthalen-2-yl)-1,3-thiazol-2-yl]-1H-indole (6g)}

Conditions: reflux for $24 \mathrm{~h}$; cycloexane/ethyl acetate 7:3; brown solid; yield 60\%; mp: 192-193 ${ }^{\circ} \mathrm{C}$; IR $3205(\mathrm{NH}) \mathrm{cm}^{-1} ;{ }^{1} \mathrm{H}$ NMR (200 MHz, DMSO-d $) \delta:{ }^{1} \mathrm{H}$ NMR (200 MHz, DMSO-d6) $\delta: 7.13(\mathrm{dt}, 1 \mathrm{H}$, $\left.J=2.6,9.2 \mathrm{~Hz}, \mathrm{H}-6^{\prime \prime}\right), 7.51-7.61$ (m, 3H, ArH), 7.93-8.13 (m, 5H, H-2", H-5, ArH), 8.23 (dd, 1H, J = 1.7, $8.6 \mathrm{~Hz}, \mathrm{ArH}), 8.28(\mathrm{~d}, 1 \mathrm{H}, J=2.9 \mathrm{~Hz}, \mathrm{ArH}), 8.64(\mathrm{~s}, 1 \mathrm{H}, \mathrm{ArH}), 11.93(\mathrm{~s}, 1 \mathrm{H}, \mathrm{NH}) ;{ }^{13} \mathrm{C} \mathrm{NMR}(50 \mathrm{MHz}$, DMSO- $d_{6}$ ) $\delta: 105.2\left(\mathrm{~d}, J_{C 6^{\prime \prime}-F}=24.4 \mathrm{~Hz}\right), 110.5(\mathrm{~d}), 110.7(\mathrm{~s}), 111.3$ (d), 113.3 (d), 113.5 (d), 113.6 (d), 124.4 (d), $124.6(\mathrm{~d}), 124.7(\mathrm{~s}), 126.2(\mathrm{~s}), 126.3\left(\mathrm{~d}, J_{\mathrm{C} 6^{\prime \prime}-F}=18.5 \mathrm{~Hz}\right), 127.6(\mathrm{~d}), 128.3\left(\mathrm{~d}, J_{C 6^{\prime \prime}-F}=3.7 \mathrm{~Hz}\right), 128.7(\mathrm{~d})$, $131.8(\mathrm{~s}), 132.6(\mathrm{~s}), 133.2(\mathrm{~s}), 133.3(\mathrm{~s}), 157.1\left(\mathrm{~s}, J_{C 5^{\prime \prime}-F}=322.8 \mathrm{~Hz}\right), 162.7(\mathrm{~s})$. Anal. Calcd. for $\mathrm{C}_{21} \mathrm{H}_{13} \mathrm{FN}_{2} \mathrm{~S}$ C (73.23\%) H (3.80\%) N (8.13\%) found C (72.98\%) H (4.17\%) N (8.31\%).

3-[4-(Naphthalen-2-yl)-1,3-thiazol-2-yl]-1H-indole (6h)

Conditions: $60^{\circ} \mathrm{C}$ for $24 \mathrm{~h}$; cycloexane/ethyl acetate 9:1; orange solid; yield $60 \%$; mp: $172-173{ }^{\circ} \mathrm{C}$; IR $2972(\mathrm{NH}) \mathrm{cm}^{-1}{ }^{1}{ }^{1} \mathrm{H}$ NMR (200 MHz, DMSO- $\left.d_{6}\right)$ 8: 7.29-7.35 (m, 2H, ArH), 7.55-7.62 (m, 3H, ArH), 7.97-8.13 (m, 3H, ArH), 8.14 (s, 1H, H-2"), 8.24-8.30 (m, 2H, H-5, ArH), 8.42-8.47 (m, 1H, ArH), 8.70 $(\mathrm{s}, 1 \mathrm{H}, \mathrm{ArH}), 11.85(\mathrm{~s}, 1 \mathrm{H}, \mathrm{NH}) ;{ }^{13} \mathrm{C}$ NMR $\left(50 \mathrm{MHz}, \mathrm{DMSO}-d_{6}\right) \delta: 110.6(\mathrm{~s}), 111.2(\mathrm{~d}), 112.2(\mathrm{~d}), 120.2(\mathrm{~s})$, 120.4 (d), 120.9 (d), 122.4 (d), 124.3 (d), 124.6 (d), 126.1 (d), 126.5 (d), 126.8 (d), 127.6 (d), 128.2 (d), 128.3 (d), 131.8 (s), 132.6 (s), 133.2 (s), 136.6 (s), 153.9 (s), 163.0 (s). Anal. Calcd. for $\mathrm{C}_{21} \mathrm{H}_{14} \mathrm{~N}_{2} \mathrm{~S} \mathrm{C}(77.27 \%) \mathrm{H}$ (4.32\%) N (8.58\%) found C (77.55\%) H (4.47\%) N (8.65\%).

\subsection{Biology Studies}

\subsubsection{Biology}

HCT 116 cells (colorectal carcinoma), MDA-MB-435 cells (melanoma) and MCF-7 cells (breast cancer) were purchased from American Type Culture Collection, Rockville, MD, USA and grown in RPMI medium supplemented with L-glutamine ( $2 \mathrm{mM}), 10 \%$ fetal bovine serum (FBS), penicillin $(100 \mathrm{U} / \mathrm{mL})$, streptomycin $(100 \mu \mathrm{g} / \mathrm{mL})$ and gentamicin $(5 \mu \mathrm{g} / \mathrm{mL})$. Cells were maintained in $\log$ phase by seeding twice a week at a density of $3 \times 10^{8}$ cells $/ \mathrm{L}$ in humidified $5 \% \mathrm{CO}_{2}$ atmosphere, at 
$37^{\circ} \mathrm{C}$. In all experiments, cells were made quiescent through overnight incubation before the treatment with the compounds or vehicle alone (control cells) No differences were found between cells treated with DMSO $0.1 \%$ and untreated cells in terms of cell number and viability.

\subsubsection{Viability Assay In Vitro}

Cytotoxic activity of the compounds against human tumor cell lines was determined by the MTT colorimetric assay based on the reduction of 3-(4,5-dimethyl-2-thiazolyl)bromide-2,5-diphenyl$2 \mathrm{H}$-tetrazolium to purple formazan by mitochondrial dehydrogenases of living cells. This method is commonly used to illustrate inhibition of cellular proliferation. Monolayer cultures were treated with various concentrations $(0.1-100 \mu \mathrm{M})$ of the drugs. Briefly, all cell lines were seeded at $2 \times 10^{4}$ cells /well in 96-well plates containing $200 \mu \mathrm{L}$ RPMI. When appropriated, cells were washed with fresh medium and incubated with the compounds in RPMI. After $72 \mathrm{~h}$ incubation, cells were washed, and $50 \mu \mathrm{L}$ FBS-free medium containing $5 \mathrm{mg} / \mathrm{mL}$ MTT were added. The medium was discarded after $2 \mathrm{~h}$ incubation at $37^{\circ} \mathrm{C}$ by centrifugation, and formazan blue formed in the cells was dissolved in DMSO. The absorbance, measured at $570 \mathrm{~nm}$ in a microplate reader (Bio-RAD, Hercules, CA, USA), of MTT formazan of control cells was taken as $100 \%$ of viability. The growth inhibition activity of compounds was defined as $\mathrm{GI}_{50}$ value which represents the $\log$ of the molar concentration of the compound that inhibits $50 \%$ cell growth. Each experiment was repeated at least three times in triplicate to obtain the mean values.

\subsubsection{Measurement of Phosphatidylserine (PS) Exposure}

The apoptosis-induced PS externalization to the cell surface was measured by flow cytometry by double staining with Annexin V-Fluorescein isothiocyanate (Annexin V-FITC)/propidium iodide (PI). Annexin V binding to phosphatidylserine is used to identify the earliest stage of apoptosis. PI, which does not enter cells with intact membranes, is used to distinguish between early apoptotic cells (Annexin V-FITC positive and PI negative), late apoptotic cells (Annexin V-FITC/PI-double positive) or necrotic cells (Annexin VFITC negative and PI positive). MCF-7 cells were treated with 3-[2-(naphthalen-2-yl)-1,3-thiazol-4-yl]-1H-indoles 4a-1 3-[2-(naphthalen-2-yl)-1,3-thiazol-4-yl]$1 H$-pyrrolo[2,3-b]pyridines $\mathbf{5 a - d}$, and 3-[4-(naphthalene-2-yl)-1,3-thiazol-2-yl]-1H-indoles $\mathbf{5 a - h}$, prepared as described above. The compounds were dissolved in dimethyl sulfoxide (DMSO) and then diluted in culture medium to have a DMSO concentration not exceeding $0.1 \%$. MCF-7 cells $\left(5.0 \times 10^{4}\right.$ cells $\left./ \mathrm{cm}^{2}\right)$ were seeded in triplicate in 24-wells culture plates. After an overnight incubation, the cells were washed with fresh medium and incubated with the compounds or vehicle alone (control cells) in RPMI for $24 \mathrm{~h}$. Then, cells were harvested by trypsinization and adjusted at $1.0 \times 10^{6} \mathrm{cells} / \mathrm{mL}$ with combining buffer according to the manufacturer' instructions (eBioscience, San Diego, CA, USA). One hundred $\mu \mathrm{L}$ of cell suspensions were added to a new tube, and incubated with Annexin V-FITC and PI solution at room temperature in the dark for $15 \mathrm{~min}$. Then samples of at least $1.0 \times 10^{4}$ cells were subjected to fluorescence-activated cell sorting (FACS) analysis by Epics XL ${ }^{\mathrm{TM}}$ flow cytometer using Expo32 software (Beckman Coulter, Fullerton, CA, USA) using appropriate bidimensional gating method.

\subsubsection{Cell Cycle Analysis}

Cell cycle stage was analyzed by flow cytometry. MCF-7 cells $\left(5.0 \times 10^{4}\right.$ cells $\left./ \mathrm{cm}^{2}\right)$ were seeded in triplicate in 24-wells culture plates. After an overnight incubation, the cells were washed with fresh medium and incubated with the compounds or vehicle alone (control cells) in RPMI for $24 \mathrm{~h}$. Then cells were harvested by trypsinization. Aliquots of $1 \times 10^{6}$ cells were washed with PBS and incubated in the dark in a PBS solution containing $20 \mu \mathrm{g} / \mathrm{mL}$ propidium iodide (PI) and $200 \mu \mathrm{g} / \mathrm{mL}$ RNase, for $30 \mathrm{~min}$, at room temperature. Then samples of at least $1.0 \times 10^{4}$ cells were subjected to FACS analysis. 


\section{Conclusions}

New thiazole nortopsentin analogs in which one of the two indole units was replaced by a naphthalyl portion were conveniently synthesized. Among these, compounds $4 \mathbf{a}, \mathbf{6} \mathbf{a}$ and $\mathbf{6} \mathbf{d}$ showed good antiproliferative activity in particular against MCF7 cell line with $\mathrm{GI}_{50}$ values in the micromolar range. Biological studies performed to clarify their mechanism of action showed that the three compounds act as pro-apoptotic agents inducing a clear shift of viable cells towards early apoptosis in MCF-7 cells after $24 \mathrm{~h}$ treatment, while not exerting necrotic effects. They also caused cell cycle perturbation with significant decrease in the percentage of cells in the G0/G1 and S phases, accompanied by a concomitant percentage increase of cells in the G2/M phase, and appearance of a subG1-cell population.

Acknowledgments: This work was financially supported by Ministero dell'Istruzione dell'Università e della Ricerca (MIUR).

Author Contributions: Barbara Parrino, Virginia Spanò, Stella Cascioferro, Anna Carbone and Alessandra Montalbano performed chemical research and analyzed the data. Alessandro Attanzio and Luisa Tesoriere performed biological research and analyzed the data. Girolamo Cirrincione, Patrizia Diana, Paola Barraja and Luisa Tesoriere participated in the design of the research and the writing of the manuscript. All authors read and approved the final manuscript.

Conflicts of Interest: The authors declare no conflict of interest.

\section{References}

1. Zheng, L.-H.; Wang, Y.-J.; Sheng, J.; Wang, F.; Zheng, Y.; Lin, X.-K.; Sun, M. Antitumor peptides from marine organism. Mar. Drugs 2011, 9, 1840-1859. [CrossRef] [PubMed]

2. Casapullo, A.; Bifulco, G.; Bruno, I.; Riccio, R. New bisindole alkaloids of the topsentin and hamacanthin classes from the Mediterranean marina sponge Rhaphisia lacazei. J. Nat. Prod. 2000, 63, 447-451. [CrossRef] [PubMed]

3. Bao, B.; Sun, Q.; Yao, X.; Hong, J.; Lee, C.; Sim, C.J.; Im, K.S.; Jung, J.H. Cytotoxic bisindole alkaloids from a marine sponge Spongosorites sp. J. Nat. Prod. 2005, 68, 711-715. [CrossRef] [PubMed]

4. Gul, W.; Hamann, M.T. Indole alkaloid marine natural products: An established source of cancer drug leads with considerable promise for the control of parasitic, neurological and other diseases. Life Sci. 2005, 78, 442-453. [CrossRef] [PubMed]

5. Dembitsky, V.M.; Gloriozova, T.A.; Poroikov, V.V. Novel antitumor agents: Marine sponge alkaloids, their synthetic analogs and derivatives. Mini-Rev. Med. Chem. 2005, 5, 319-336. [CrossRef] [PubMed]

6. Li, X.; Li, J.-R.; Chen, K.; Zhu, H.-L. A Functional Scaffold in Marine Alkaloid: An Anticancer Moiety for Humans. Curr. Med. Chem. 2013, 20, 3903-3922. [CrossRef] [PubMed]

7. Newman, D.J.; Cragg, G.M. Natural product scaffolds as leads to drugs. Future Med. Chem. 2009, 1, 1415-1427. [CrossRef] [PubMed]

8. Singla, R.; Negi, A.; Singh, V. Indole based alkaloid in cancer: An overview. PharmaTutor Mag. 2014, 2, 76-82.

9. Ma, D.-L.; Chan, D.S.-H.; Leung, C.-H. Drug repositioning by structure-based virtual screening. Chem. Soc. Rev. 2013, 42, 2130-2141. [CrossRef] [PubMed]

10. Sun, H.H.; Sakemi, S.; Gunasekera, S.; Kashman, Y.; Lui, M.; Burres, N.; McCarthy, P. Bis-Indole Imidazole Compounds Which Are Useful Antitumor and Antimicrobial Agents. U.S. Patent 4970226, 13 November 1990.

11. Kobayashi, J.; Murayama, T.; Ishibashi, M.; Kosuge, S.; Takamatsu, M.; Ohizumi, Y.; Kobayashi, H.; Ohta, T.; Nozoe, S.; Sasaki, T. Hyrtiosins A and B, new indole alkaloids from the Okinawan marine sponge Hyrtios erecta. Tetrahedron 1990, 46, 7699-7702. [CrossRef]

12. Shimizu, S.; Yamamoto, Y.; Inagaki, L.; Koshimura, S. Antitumor effect and structure-activity relationship of asterriquinone analogs. Gann 1982, 73, 642-648. [PubMed]

13. Kohmoto, S.; Kashman, Y.; McConnel, O.J.; Rinehart, K.L., Jr.; Wrigh, A.; Koehn, F. Dragmacidin, a new cytotoxic bis(indole)alkaloid from a deep water marine sponge, Dragmacidon sp. J. Org. Chem. 1988, 53, 3116-3118. [CrossRef] 
14. Bartik, K.; Braekman, J.C.; Daloze, D.; Stoller, C.; Huysecom, J.; Vandevyver, G.; Ottinger, R. Topsentin, new toxic bis-indole alkaloids from the marine sponge Topsentia genitrix. Can. J. Chem. 1987, 65, 2118-2121. [CrossRef]

15. Sakemi, S.; Sun, H.H. Nortopsentins A, B and C. Cytotoxic and antifungal imidazolediylbis[indoles] from the sponge Spongosorites ruetzleri. J. Org. Chem. 1991, 56, 4304-4307. [CrossRef]

16. Kawasaki, I.; Yamashita, M.; Ohta, S. Total synthesis of nortopsentins A-D marine alkaloids. Chem. Pharm. Bull. 1996, 44, 1831-1839. [CrossRef]

17. Moody, C.J.; Roffey, J.R.A. Synthesis of N-protected Nortopsentins B and D. Arkivoc 2000, 1, $393-401$.

18. Miyake, F.Y.; Yakushijin, K.; Horne, D.A. A concise synthesis of topsentin A and nortopsentin B and D. Org. Lett. 2000, 2, 2121-2123. [CrossRef] [PubMed]

19. Fresneda, P.M.; Molina, P.; Sanz, M.A. Microwave-assisted regioselective synthesis of 2,4-disubstituted imidazoles: Nortopsentin D synthesized by minimal effort. Synlett 2001, 2, 218-221. [CrossRef]

20. Diana, P.; Carbone, A.; Barraja, P.; Montalbano, A.; Martorana, A.; Dattolo, G.; Gia, O.; Dalla Via, L.; Cirrincione, G. Synthesis and antitumor properties of 2,5-bis(3'-indolyl)thiophenes: Analogues of marine alkaloid nortopsentin. Bioorg. Med. Chem. Lett. 2007, 17, 2342-2346. [CrossRef] [PubMed]

21. Diana, P.; Carbone, A.; Barraja, P.; Martorana, A.; Gia, O.; Dalla Via, L.; Cirrincione, G. 3,5-Bis(3'-indolyl)pyrazoles, analogues of marine alkaloid nortopsentin: Synthesis and antitumor properties. Bioorg. Med. Chem. Lett. 2007, 17, 6134-6137. [CrossRef] [PubMed]

22. Diana, P.; Carbone, A.; Barraja, P.; Kelter, G.; Fiebig, H.H.; Cirrincione, G. Synthesis and antitumor activity of 2,5-bis(3'-indolyl)-furans and 3,5-bis(3'-indolyl)-isoxazoles, nortopsentin analogues. Bioorg. Med. Chem. 2010, 18, 4524-4529. [CrossRef] [PubMed]

23. Carbone, A.; Parrino, B.; Barraja, P.; Spanò, V.; Cirrincione, G.; Diana, P.; Maier, A.; Kelter, G.; Fiebig, H.H. Synthesis and antiproliferative activity of 2,5-bis(3'-indolyl)pyrroles, analogues of the marine alkaloid nortopsentin. Mar. Drugs 2013, 11, 643-654. [CrossRef] [PubMed]

24. Kumar, D.; Kumar, N.M.; Chang, K.H.; Gupta, R.; Shah, K. Synthesis and in vitro anticancer activity of 3,5-bis(indolyl)-1,2,4-thiadiazoles. Bioorg. Med. Chem. Lett. 2011, 21, 5897-5900. [CrossRef] [PubMed]

25. Jacquemard, U.; Dias, N.; Lansiaux, A.; Bailly, C.; Logè, C.; Robert, J.M.; Lozach, O.; Meijer, L.; Merour, J.Y.; Routier, S. Synthesis of 3,5-bis(2-indolyl)pyridine and 3-[(2-indolyl)-5-phenyl]pyridine derivatives as CDK inhibitors and cytotoxic agents. Bioorg. Med. Chem. 2008, 16, 4932-4953. [CrossRef] [PubMed]

26. Diana, P.; Carbone, A.; Barraja, P.; Montalbano, A.; Parrino, B.; Lopergolo, A.; Pennati, M.; Zaffaroni, N.; Cirrincione, G. Synthesis and antitumor activity of 3-(2-phenyl-1,3-thiazol-4-yl)-1H-indoles and 3-(2-phenyl-1,3-thiazol-4-yl)-1H-7-azaindoles. ChemMedChem 2011, 6, 1300-1309. [CrossRef] [PubMed]

27. Carbone, A.; Pennati, M.; Barraja, P.; Montalbano, A.; Parrino, B.; Spanò, V.; Lopergolo, A.; Sbarra, S.; Doldi, V.; Zaffaroni, N.; et al. Synthesis and antiproliferative activity of substituted 3[2-(1H-indol-3-yl)1,3-thiazol-4-yl]-1H-pyrrolo[3,2-b]pyridines, marine alkaloid nortopsentin analogues. Curr. Med. Chem. 2014, 21, 1654-1666. [CrossRef] [PubMed]

28. Carbone, A.; Pennati, M.; Parrino, B.; Lopergolo, A.; Barraja, P.; Montalbano, A.; Spanò, V.; Sbarra, S.; Doldi, V.; de Cesare, M.; et al. Novel 1H-pyrrolo[2,3-b]pyridine derivatives nortopsentin analogues: Synthesis and antitumor activity in peritoneal mesothelioma experimental models. J. Med. Chem. 2013, 56, 7060-7072. [CrossRef] [PubMed]

29. Carbone, A.; Parrino, B.; di Vita, G.; Attanzio, A.; Spanò, V.; Montalbano, A.; Barraja, P.; Tesoriere, L.; Livrea, M.A.; Diana, P.; et al. Synthesis and antiproliferative activity of thiazolyl-bis-pyrrolo[2,3- $b$ ]pyridines and indolyl-thiazolyl-pyrrolo[2,3-c]pyridines, nortopsentin analogues. Mar. Drugs 2015, 13, 460-492. [CrossRef] [PubMed]

30. Parrino, B.; Carbone, A.; Di Vita, G.; Ciancimino, C.; Attanzio, A.; Spanò, V.; Montalbano, A.; Barraja, P.; Tesoriere, L.; Diana, P.; et al. 3-[4-(1H-Indol-3-yl)-1,3-thiazol-2-yl]-1H-pyrrolo[2,3-b]pyridines, nortopsentin analogues with antiproliferative activity. Mar. Drugs 2015, 13, 1901-1924. [CrossRef] [PubMed]

31. Mahboobi, S.; Uecker, A.; Sellmer, A.; Cenac, C.; Hoecher, H.; Pongratz, H.; Eichhorn, E.; Hufsky, H.; Truempler, A.; Sicker, M.; et al. Novel Bis(1H-indol-2-yl)-methanones as potent inhibitors of FLT3 and platelet-derived growth factor receptor tyrosine kinase. J. Med. Chem. 2006, 49, 3101-3115. [CrossRef] [PubMed] 
32. Campbell, A.N.; Meyer, E.B.; Stahl, S.S. Regiocontrolled aerobic oxidative coupling of indoles and benzene using Pd catalysts with 4,5-diazafluorene ligands. Chem. Commun. 2011, 47, 10257-10259. [CrossRef] [PubMed]

33. Ottoni, O.; Cruz, R.; Alves, R. Efficient and simple methods for the introduction of the sulfonyl, acyl and alkyl protecting groups on the nitrogen of indole and its derivatives. Tetrahedron 1998, 54, 13915-13928. [CrossRef]

34. Johnson, A.L.; Bergmann, J. Synthetic approaches towards an indole alkaloid isolated from the marine sponge Halichondria melanodocia. Tetrahedron 2006, 62, 10815-10820. [CrossRef] 